\title{
Integration of signaling information in controlling cell-fate decisions in Dictyostelium
}

\author{
Richard A. Firtel \\ Department of Biology, Center for Molecular Genetics, University of California, San Diego, La Jolla, California 92093-0634 \\ USA
}

Over the last few years, a combination of genetic, molecular, and biochemical approaches has led to significant new insights into the regulation of development in Dictyostelium and has uncovered new pathways that may also control developmental decisions in other systems. In Dictyostelium, the vegetative growth and the multicellular developmental portions of the life cycle are separated; wild-type Dictyostelium strains are haploid, and multicellular development, which is initiated by starvation, takes place in the absence of cell division. Thus, many genes that are essential for the multicellular phase have no effect on growth, facilitating genetic analysis of gene products essential for multicellular development. The general developmental program of Dictyostelium is depicted in Figure 1.

Dictyostelium is an ideal organism for studying how signaling pathways are integrated to control morphogenesis and gene regulation, and much of the recent progress in understanding the control of multicellular development in Dictyostelium is a result of linking the various components into regulatory networks. The identification and functional analysis of stage and cell-type-specific $G$ proteins, serpentine ( $G$ protein-coupled) receptors, the transcription factor GBF (G-box-binding factor), MAP (mitogen-activated protein) kinases, PKA (protein kinase $\underline{\mathrm{A}}$ ), GSK-3 (glycogen synthase kinase-3) (the latter two control cell-fate decisions in Drosophila), and other signaling molecules common to all eukaryotes have provided basic, new insights into control of these processes in Dictyostelium and other systems. In addition, novel pathways have been identified that are regulated by extracellular cAMP functioning through serpentine receptors to activate distinctly different developmental pathways, depending on whether the cells perceive a pulsatile or sustained signal. This has led to an initial understanding of how signaling and transcriptional events are integrated to control developmental timing and how cell-type specification is regulated by these factors and extracellular morphogens.

This review examines these recent findings and describes how they have led to a new understanding of the molecular mechanisms regulating the developmental de- cisions in Dictyostelium and their relationship to developmental decisions in other organisms.

\section{Formation of the multicellular organism}

Multicellular development is initiated several hours after removal of the food source, when a small number of cells within the population emit an extracellular pulse of cAMP. Cells respond by chemotaxis toward the signal and activation of adenylyl cyclase (AC) to produce more cAMP, which is secreted/released (Devreotes 1994). Cyclic AMP binding to receptors on outlying cells relays the signal, whereas binding to additional receptors on the activated cell amplifies the signal. Like receptor-coupled pathways in other systems, the responses are transient; they adapt within 1-2 min, and the cells regain responsiveness to cAMP in 5-6 min. About 20-30 pulses (cycles of activation and adaptation of the pathways) are required for an aggregation domain to produce a mound. In addition to regulating the relay of the CAMP signal and chemotaxis, the cAMP pulses also induce expression of genes required for aggregation (pulse-induced genes), as described below.

Adaptation of the aggregation responses is crucial because this provides directionality to the chemotactic movement toward the aggregation center. The rapid adaptation ensures that cells respond only to cAMP from the direction of the aggregation center and not to cAMP secreted by outlying cells (Tomchik and Devreotes 1981; Van Haastert et al. 1987). As long as cAMP is present, the pathways remain adapted. To remove extracellular cAMP, aggregation-stage Dictyostelium cells express an extracellular phosphodiesterase (PDE), which rapidly hydrolyzes the extracellular cAMP (Franke and Kessin 1992). The level of active PDE is tightly regulated both at the level of transcription and via a phosphodiesterase inhibitor (PDI, which binds to and inhibits the PDE), because high levels of PDE would interfere with diffusion of CAMP to adjacent cells and low levels would result in the sustained presence of CAMP and prolonged adaptation. High levels of cAMP stimulate PDE expression and inhibit the expression of PDI, whereas low lev- 
Figure 1. The developmental cycle is shown. The first panel shows spore germination. A dark-field image of an aggregation domain is shown at $6 \mathrm{hr}$. Developing mounds are seen at $8 \mathrm{hr}$ and $10 \mathrm{hr}$, and a tipped aggregate at $12 \mathrm{hr}$. At $14 \mathrm{hr}$, a finger has formed that falls over to become the slug (16 hr). Culmination ensues at $18 \mathrm{hr}$, and a mature fruiting body is formed by 24 hr. The developmental phases are shown with the periodicity of cAMP production. (Bottom) The developmental kinetics of gene expression, emphasizing the transcriptional changes at the time of mound formation. At the initiation of development by starvation, a set of genes are induced that are then repressed by pulses of cAMP. These pulses induce another set of genes (pulse-induced genes) that play essential roles during aggregation. As the mound forms, these pulse-induced genes are repressed and the developmental cascade leading to cell-type differentiation is initiated by the induction of GBF followed by the postaggregative or primary-response genes and the cell-type-specific genes. (See text for details.) els of cAMP stimulate PDI expression (Franke and Kessin 1992). The regulatory gene products discussed in this review are described in Table 1.

\section{A series of integrated signaling pathways regulates aggregation}

Analysis of the signaling pathways that regulate aggregation in Dictyostelium provides general insight into eukaryotic receptor-regulated pathways, including chemotaxis in mammalian cells (Devreotes and Zigmond 1988). cAMP binds to classic serpentine cell-surface receptors (CAMP receptors or cARs) that couple to the heterotrimeric $G$ protein containing the $G \alpha$ subunit $G \alpha 2$ (Fig. 2). Three second-messenger pathways are activated: guanylyl cyclase (GC), phospholipase C (PLC), and AC (Devreotes 1994). AC activity peaks at $\sim 90 \mathrm{sec}$ and then adapts, whereas GC and PLC peak and adapt more rapidly (10 and $7 \mathrm{sec}$, respectively). Continuous fluxes of cAMP cause a single, transient activation of these pathways, followed by the eventual down-regulation of the receptors. Analysis of null strains indicates that the receptor and the $G$ protein are essential for these responses in vivo (Kumagai et al. 1989, 1991; Kesbeke et al. 1990; Sun and Devreotes 1991; Wu et al. 1995). cAR1, the most abundant cAR during aggregation, has a high affinity for cAMP and is able to respond to the low concentrations of cAMP present during the early stages (Johnson et al. 1992; Insall et al. 1994b). cAR3, a lower affinity cAR, can replace $\mathrm{CAR} 1$; however, higher concentrations of cAMP are required to activate the responses (Insall et al. 1994a). This indicates that multiple cARs couple to $\mathrm{G} \alpha 2$ and can regulate the same signaling pathways.

The activation of $\mathrm{AC}$ is regulated via a fairly complex pathway. The AC expressed during aggregation (ACA) has the same predicted structure as mammalian ACs (Pitt et al. 1992; Tang and Gilman 1992) and is thought to be directly regulated by the G $\beta \gamma$ subunit rather than a specific $\mathrm{G} \alpha$ subunit. Several lines of evidence support this conclusion. In vivo, cAMP activation of $A C$ requires $\mathrm{G} \alpha 2$, whereas in vitro, $A C$ can be activated in go2 but not $g \beta$ null cells by GTP $\gamma S$ (Kesbeke et al. 1988; Kumagai et al. 1991; Wu et al. 1995). Overexpression of $\mathrm{G} \alpha 2$ suppresses the activation of $\mathrm{AC}$ but stimulates the activation of GC (Okaichi et al. 1992). At least two other components are required for $\mathrm{AC}$ activation in Dictyostelium: the MAP kinase ERK2 and a cytosolic protein, CRAC (Lilly and Devreotes 1994; Segall et al. 1995). CRAC has a pleckstrin domain, suggesting that it interacts with another protein, possibly the G $\beta$ subunit (Insall et al. 1994a; Touhara et al. 1994). MAP kinases are known to be activated through both receptor tyrosine kinases and G protein-coupled receptors (Davis 1993; Errede and Levin 1993; Blumer and Johnson 1994) but have not been known previously to be required for the activation of $\mathrm{AC}$.

Activation of GC and production of cGMP have been linked to chemotaxis and the membrane-associated polymerization of actin and myosin, similar to pathways mediating chemotaxis in mammalian cells (McRobbie and Newell 1984; Devreotes and Zigmond 1988; Liu et al. 1993). Mutations affecting the GC/cGMP pathway result in cells that are not capable of chemotaxis or that show altered chemotaxis but activate AC normally (Newell and Liu 1992; Kuwayama et al. 1993). The gene encoding PLC has been disrupted, but there is no developmental phenotype, suggesting that PLC activity is not required for aggregation or other stages in development (Drayer et al. 1994). For a more detailed analysis, the reader is referred to a recent review of this pathway (Devreotes 1994). 
Table 1. Regulatory function of cloned genes described in text

\begin{tabular}{|c|c|}
\hline \multicolumn{2}{|l|}{ Aggregation } \\
\hline cAR 1 & high-affinity cAMP receptor; required for all aggregation responses to nanomolar pulses of cAMP \\
\hline cAR3 & lower affinity cAMP receptor; can mediate aggregation-stage responses but only to higher levels of cAMP \\
\hline $\mathrm{G} \alpha 2$ & $\mathrm{G} \alpha$ subunit; couples to $\mathrm{cARl}$; required for all cAMP-aggregation responses \\
\hline CRAC & cytosolic activator of adenylyl cyclase $(\mathrm{AC})$, required for $\mathrm{G}$-protein activation of $\mathrm{AC}$ \\
\hline $\mathrm{G} \beta$ & $\begin{array}{l}\mathrm{G} \beta \text { subunit; required for all cAMP-aggregation and folate-mediated responses except } \mathrm{Ca}^{2+} \text { influx and } \\
\text { activation of the GBF pathway; no activation of } \mathrm{AC} \text {, guanylyl cyclase }(\mathrm{GC}) \text {, or chemotaxis }\end{array}$ \\
\hline ERK2 & MAP kinase; required for AC stimulation \\
\hline $\mathrm{ACA}$ & adenylyl cyclase $(\mathrm{AC})$ gene expressed during aggregation; required for production of cAMP and signal relay \\
\hline CMF & conditioned medium factor; senses cell density; required for aggregation \\
\hline PKAcat & $\begin{array}{l}\text { catalytic subunit of cAMP-dependent protein kinase (PKA); required for AC activity; also required for other } \\
\text { processes in aggregation }\end{array}$ \\
\hline GC & $\begin{array}{l}\text { guanylyl cyclase }(\mathrm{GC}) \text {; activity involved in actin/myosin mobilization and chemotaxis in response to cAMP, } \\
\text { folate, and other chemoattractants }\end{array}$ \\
\hline PDE & $\begin{array}{l}\text { extracellular phosphodiesterase; required for regulating cAMP levels; overexpression or a null mutant blocks } \\
\text { aggregation }\end{array}$ \\
\hline ERK1 & $\begin{array}{l}\text { MAP kinase; overexpression of ERKI in a null mutation of the protein-tyrosine phosphatase PTP2 results } \\
\text { in very large aggregation streams that split into very small aggregates that arrest }\end{array}$ \\
\hline PTP2 & $\begin{array}{l}\text { protein-tyrosine phosphatase; null cells produce larger aggregation streams and larger slugs; phenotype } \\
\text { suggests that PTP2 affects signal relay }\end{array}$ \\
\hline PTPl & protein-tyrosine phosphatase; cells overexpressing very high levels of PTPl do not aggregate \\
\hline \multicolumn{2}{|l|}{ Mound/tip } \\
\hline GBF & transcription factor required for all late gene expression; activated by extracellular cAMP \\
\hline $\mathrm{cAR} 1 / \mathrm{cAR} 3$ & required for cAMP activation of GBF function and postaggregative development \\
\hline cAR2 & cAMP receptor; induced at mound stage and required for tip formation; null cells overexpress prespore genes \\
\hline LagC & putative cell-surface ligand; required for prespore and prestalk cell differentiation \\
\hline PKAcat & required for prestalk and prespore gene expression \\
\hline ras $D$ & involved in tip formation \\
\hline $\mathrm{G} \alpha 4$ & couples to folate receptors; null cells arrest at finger stage; required for prespore/spore pathway \\
\hline PTPl & protein-tyrosine phosphatase; overexpression of PTP1 results in aggregates with multiple tips \\
\hline PDE & phosphodiesterase; overexpression blocks tip formation, indicates importance of cAMP in this process \\
\hline PTP2 & protein-tyrosine phosphatase; overexpression of PTP2 results in aggregates that arrest at the mound stage \\
\hline \multicolumn{2}{|l|}{ Prespore cells } \\
\hline GSK-3 & glycogen synthase kinase-3; required for prespore cell formation \\
\hline $\mathrm{G} \alpha 4$ & required for normal expression of prespore genes and spore formation \\
\hline $\mathrm{cAR} 2 / \mathrm{cAR} 4$ & $\begin{array}{l}\text { null strains for either receptor show overexpression of prespore markers and a reduced expression of prestalk } \\
\text { markers; phenotype suggests that it is involved in prestalk differentiation and inhibiting prespore cell } \\
\text { differentiation }\end{array}$ \\
\hline \multicolumn{2}{|r|}{ ( } \\
\hline GSK-3 & negative regulator of prestalk $B$ differentiation \\
\hline $\mathrm{cAR} 2 / \mathrm{cAR} 4$ & see above \\
\hline \multicolumn{2}{|l|}{ Slug } \\
\hline $\mathrm{G} \alpha \mathrm{l}$ & $\begin{array}{l}\text { G } \alpha \text {-subunit; overexpression results in abnormal slug morphology and reduced/no prestalk B cell gene } \\
\text { expression; negative regulator of prestalk B differentiation? }\end{array}$ \\
\hline $\mathrm{G} \alpha 7$ & G $\alpha$-subunit; overexpression results in abnormal slug morphology and culmination \\
\hline ERK1 & overexpression alters slug morphology and culmination; increased number of rear guard cells \\
\hline PTPl & overexpression of PTP1 results in slugs with large, bulbous anteriors \\
\hline \multicolumn{2}{|l|}{ Culmination } \\
\hline $\mathrm{G} \alpha 2$ & $\begin{array}{l}\text { expression of a dominant-negative G } \alpha 2 \text { results in abnormal stalk morphogenesis during culmination; } \\
\text { indicates a role for both cAMP receptors and G-protein-coupled pathways }\end{array}$ \\
\hline $\mathrm{G} \alpha 1$ & $\begin{array}{l}\text { expression of a constitutively active G } \alpha 1 \text {-subunit results in abnormal morphogenesis during culmination; } \\
\text { activity required for the rise in 1,2-diacylglycerol levels associated with the induction of culmination }\end{array}$ \\
\hline cAR4 & cAMP receptor; required for proper culmination and spatial patterning; null cells overexpress prespore genes \\
\hline PKAcat & $\begin{array}{l}\text { required for prestalk } \rightarrow \text { stalk and prespore } \rightarrow \text { spore differentiation; overexpression in prespore cells induces } \\
\text { spore differentiation very early in development; preferentially expressed in prestalk A cells in slug and } \\
\text { prespore cells in culminant }\end{array}$ \\
\hline
\end{tabular}

\section{Aggregation competence, developmental timing, and regulation of gene expression}

Although addition of cAMP to washed, vegetative cells results in the stimulation of $A C$ and $G C$, the levels of activation are low, resulting from a low level of the essential signaling components at this stage of development, and there is no effective chemotaxis of the cells to cAMP (Kesbeke et al. 1986; Okaichi et al. 1992). Genes encoding several of these components (cAR1, G $\alpha 2, P K A)$ 
Figure 2. cAMP receptor-mediated pathways during aggregation and multicellular development. During aggregation, cAMP binds to cAR 1 and activates GC, PLC, AC, and pulse-induced gene expression. The pathway is drawn with a direct coupling of GC and PLC to the G protein containing $\mathrm{G} \alpha 2$, although this has not been proven. $A C$ is thought to be activated by G $\beta \gamma$, and this activation is known to require CRAC, the cyctosolic activator of $A C$, and the MAP kinase ERK2. In vivo, all responses require both the $G \beta$ subunit and $G \alpha 2$. In addition, cAMP binding results in a $\mathrm{Ca}^{2+}$ influx, which is $\mathrm{G}$ protein-independent. The function of this pathway is not known. In the multicellular stages, activation of late gene expression occurs through cARs but is independent of $G$ proteins. cAMP response pathways similar to those present during aggregation may regulate morphogenesis during tip formation and culmination through $\mathrm{G} \alpha 2$. Other $\mathrm{G} \alpha$ subunits and other $G$ protein-independent pathways may interact with cAR2, cAR4, and other serpentine receptors. Data are from Schnitzler et al. (1995).

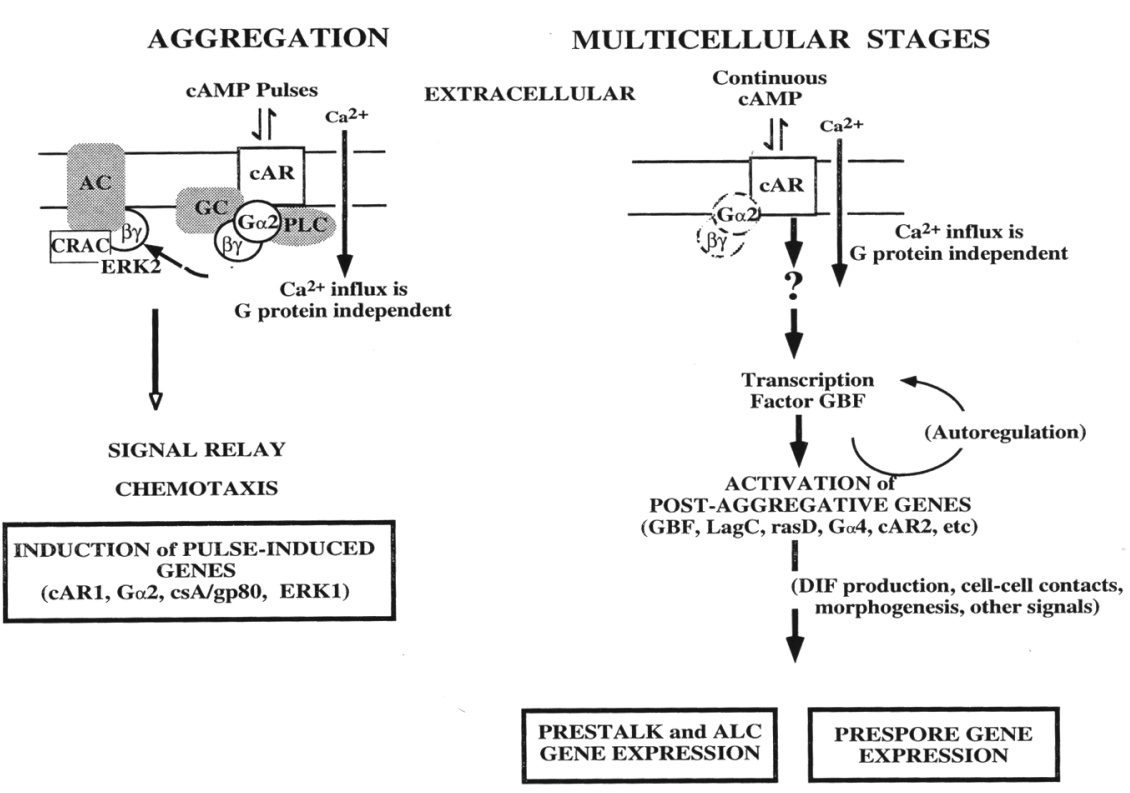

belong to the "pulse-induced" class of genes (Kimmel and Firtel 1991). Low-level transcription of the pulseinduced genes is activated by starvation and requires a secreted protein factor, conditioned media factor $(\mathrm{CMF})$, which functions as a density-sensing factor to ensure that the concentration of cells is sufficient for successful chemotaxis and aggregation (Gomer et al. 1991; Yuen et al. 1991). This starvation-mediated response leads to a sufficient level of receptors and other components to initiate signaling. As waves of cAMP move through the population, expression of this class of genes is rapidly induced to a significantly higher level. The pathway shows positive autoregulation in that proteins that are induced are required for their own induction (e.g., cAR 1 and $\mathrm{G} \alpha 2$ ). As with the other aggregation-stage pathways, a continuous cAMP signal blocks this induction (Mann and Firtel 1989|. If the pulsatile cAMP signal is switched to a high, continous signal, the pulse-induced genes are rapidly repressed (Mann and Firtel 1989; Schnitzler et al. 1995). The timing of pulse-induced gene expression is shown in Figure 1.

The ability to mimic the in vivo oscillatory pattern of cAMP by adding exogenous cAMP to cell suspension cultures has allowed a determination of which components of the aggregation-response pathways are required for pulse-induced gene expression. Cells in which AC activation is defective, such as cAMP-dependent PKA, CRAC, or ACA null cells, cannot aggregate by themselves but will respond chemotactically to cAMP pulses and induce early gene expression (Mann and Firtel 1991; Pitt et al. 1992; Insall et al. 1994a). These cells can aggregate with wild-type cells to form a chimeric organism, and some will participate in spore formation, although at a low frequency. Together, these results indi- cate that intracellular cAMP is not required for pulseinduced gene induction. As with other aggregation-stage responses, either CAR1 or CAR3 is required for this induction (Soede et al. 1994). We expect that the pathway will involve the integration of multiple, transient responses over a period of time. Such a pathway has been defined in mammalian neuronal cell lines in which $\mathrm{Ca}^{2+} /$ calmodulin kinase is activated by multiple, transient increases in intracellular $\mathrm{Ca}^{2+}$ that, on reaching a threshold concentration, activate the enzyme to a high level (Meyer et al. 1994).

\section{Spatial localization of cell types-cell sorting and morphogenesis}

As the mound forms, there is a developmental switch from the formation of a multicellular organism to the induction of the specific cell types that are the precursors of cells found within the mature fruiting body. This switch is marked molecularly by the induction of postaggregative and then cell-type-specific genes (Fig. 1). A "fate map" has been constructed throughout the multicellular stages using $l a c Z$ and $\beta$-glucuronidase (GUS) reporter constructs driven by promoters for a number of these genes (Fig. 3; Gomer et al. 1986b; Dingermann et al. 1989; Haberstroh and Firtel 1990; Jermyn and Williams 1991; Esch et al. 1992; Early et al. 1993). Early studies defined three major cell types in the migrating slug: prestalk cells, preferentially located in the anterior $15 \%$ of the slug; prespore cells, located in the posterior $75 \%$; and anterior-like cells (ALCs), a population of cells $(5 \%-10 \%)$ scattered throughout the organism with some properties of prestalk cells (Loomis 1982; Sternfeld and David 1982). Analysis of promoters for the prestalk genes ecm $A$ and $e c m B$ has now defined multiple classes of 


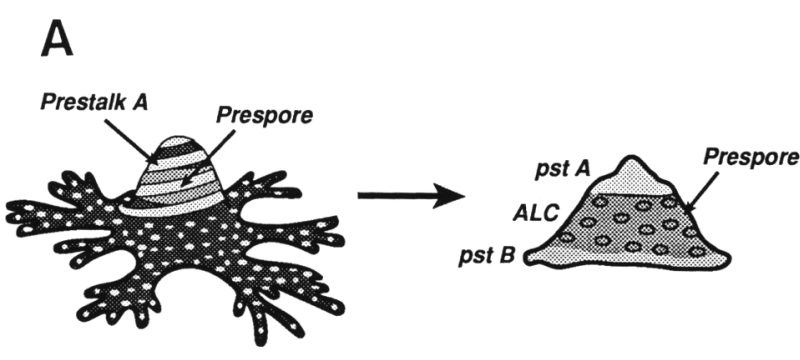

B
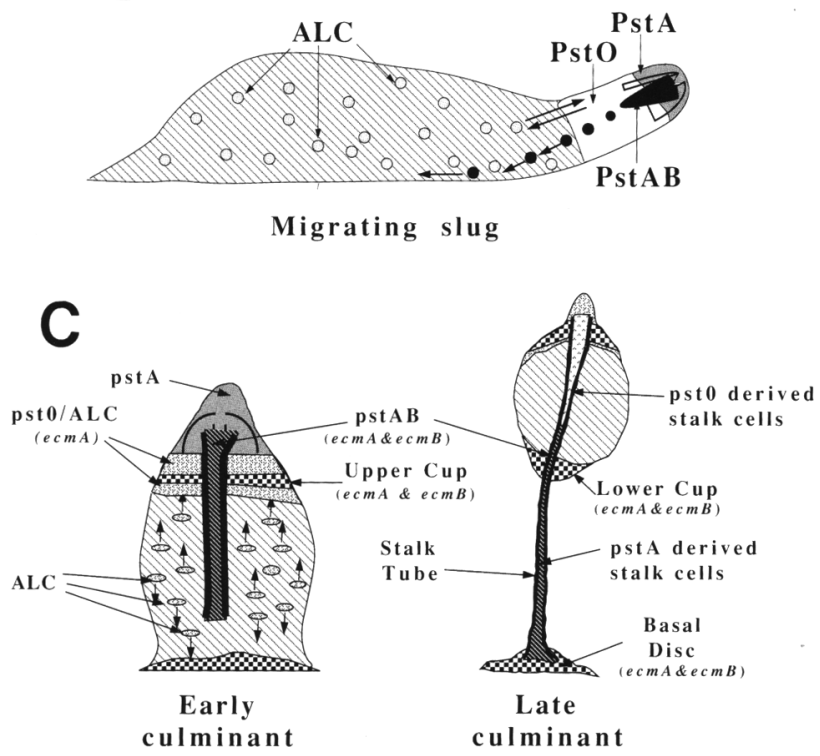

Figure 3. Fate map of cell types during Dictyostelium development. (A) The formation of the initial prestalk and prespore patterns as the mound is forming. (Left) The patterning as cells are still moving into the mound and as the tip is forming. The prestalk cells become localized in the tip by differential sorting (see text) and can be seen to move in a spiral pattern, presumably following the spiral waves of cAMP. The localization of the prespore cells is also shown. The unlabeled, darker region represents cells that have not expressed cell-type-specific markers. (Right) The initial pattern of prestalk and prespore cells in the tipped aggregate and the presence of ALCs (small circles) in the organism. The cartoon is derived from the analysis of the whole ecm $A$ (prestalk $A$ and $O$, defined here using the original terminology of prestalk A cells), ecmB (prestalk B), and the SP6O (prespore) promoters. Results describing the inital patterning of prestalk A compared with prestalk $O$ cells have not been published. $(B, t o p)$ The patterning of the cell types in the slug and the movement and interconversion of prestalk and ALCs / see text; Abe et al. 1994 for details). $(C)$ The patterning during culmination. The drawings in part were a gift of J. Williams (MRC Laboratory for Molecular Biology, London, UK).

prestalk cells (Williams et al. 1993b). The ALC population is also complex, with different subpopulations expressing different combinations of ecmA and ecmB, as well as some regulatory genes including ERK1, PTP1, PTP2, and Ga4 (see below; Jermyn and Williams 1991; Howard et al. 1992, 1994; Gaskins et al. 1994; Hadwiger et al. 1994). The functions of these genes are described below and in Table 1. A listing of the cell-type-specific markers is presented in Table 2.

Prespore-specific promoters (see Table 2) show a homogeneous expression over the posterior $\sim 85 \%$ of the slug (Dingermann et al. 1989; Haberstroh and Firtel 1990; Fosnaugh and Loomis 1993; Powell-Coffman and Firtel 1994). However, various CotC/SP60 promoter deletions show anterior-to-posterior or posterior-to-anterior gradients of expression, suggesting that differences exist within the prespore domain (Haberstroh and Firtel 1990; Haberstroh et al. 1991). Moreover, when cells from the back, middle, and front of the prespore region were marked and transplanted into other slugs, differences in behavior of the cells were observed (Buhl et al. 1993). Taken together, these results suggest the existence of gradients of morphogens within the prespore domain that differentially affect promoter elements and lead to the behavioral differences of the cells.

The spatial patterning of prestalk and prespore cells within the mound arises from the sorting of the prestalk cells to the presumptive tip of the mound (Williams et al. 1989; Esch and Firtel 1991; Williams and Jermyn 1991). This appears to be mediated by cAMP using pathways that may be identical to those that mediate chemotaxis during aggregation, with prestalk cells having an inherently higher rate of chemotactic movement than prespore cells (Mee et al. 1986). Inversion of the putative apical-to-basal cAMP gradient (achieved by placing mounds on agar having a high concentration of cAMP) results in sorting of prestalk cells to the base, wheres disruption of the gradient by overexpressing PDE from its own prestalk-specific late promoter (and thus reducing cAMP around these cells) blocks tip formation (Traynor et al. 1992; Hall et al. 1993). Strains lacking the gene encoding the cAMP receptor cAR2, which is preferentially expressed in prestalk cells, arrest at the mound stage, with a few aggregates developing a tip, suggesting that cAR2 mediates cell sorting during tip formation (Saxe et al. 1993).

The apical tip functions as an "organizer" that controls subsequent morphogenesis and is the source of the cAMP wave that is thought to initiate at the tip and move toward the posterior (Siegert and Weijer 1991, 1992). It acts as a center for the sorting of the prestalk cells and inhibits other oscillators from forming by down-regulating the cAMP relay within the remainder of the aggregate (Wang and Schaap 1985). Wild-type strains form only a single tip. Mutant strains that initially form multiple tips either developmentally arrest, as observed for cells overexpressing the constitutively active RasD(G12T) mutation (Reymond et al. 1986), or each tip "organizes" an independent organism that separates and migrates apart, as in the case of strains that overexpress the protein-tyrosine phosphatase PTP1 (Howard et al. 1992).

As the mound forms, there is an increase in the level of intercellular cAMP, which adapts aggregation-stage pathways mediated through the cARl high-affinity receptor (see above). How is an oscillator maintained if these pathways are adapted by the high level of cAMP? 
Table 2. Cell type-specific markers described in text

\begin{tabular}{|c|c|}
\hline \multicolumn{2}{|l|}{ Prestalk } \\
\hline$e c m A$ & extracellular matrix protein; prestalk A/O, ALCs \\
\hline$e c m B$ & $\begin{array}{l}\text { extracellular matrix protein; expressed in prestalk B cells and ALCs; a deletion of } e c m B \text { promoter } \\
(e c m B \Delta 89) \text { is expressed specifically in stalk cells }\end{array}$ \\
\hline $\mathrm{G} \alpha 1$ & G $\alpha$-subunit; shows same pattern of expression as $e \mathrm{~cm} B$ \\
\hline \multicolumn{2}{|l|}{ ALCs } \\
\hline $\mathrm{G} \alpha 4$ & Go-subunit \\
\hline PTP1, PTP2 & $\begin{array}{l}\text { protein-tyrosine phosphatases; PTP1 and PTP2 are distinct and have different developmental } \\
\text { functions }\end{array}$ \\
\hline ERK1 & MAP kinase \\
\hline$e c m A / e c m B$ & $\begin{array}{l}e c m A \text { and } e c m B \text { encode extracellular matrix proteins; they are also markers for prestalk } \mathrm{A} / \mathrm{O} \text { and } \\
\text { prestalk B cells, respectively }\end{array}$ \\
\hline $\mathrm{Gal}$ & Gal shows a similar pattern of expression as ecmB \\
\hline \multicolumn{2}{|l|}{ Prespore } \\
\hline SP60/CotC & spore coat protein \\
\hline SP70/CotB & spore coat protein \\
\hline PspB & spore coat protein \\
\hline PspA & cell-surface-associated protein \\
\hline \multicolumn{2}{|c|}{ Prestalk-enriched } \\
\hline $\mathrm{CP} 2$ & $\mathrm{CP} 2 /$ pst-cathepsin; encodes a cysteine protease \\
\hline ras $D$ & encodes one of five Ras proteins \\
\hline cAR1 & cAMP receptor; the cAR1 late promoter is preferentially expressed in prestalk cells \\
\hline $\mathrm{cAR} 2 / 4$ & $\begin{array}{l}\text { cAMP receptors; both receptors are induced after mound formation; cAR2 is expressed before cAR4 } \\
\text { and from genetic analysis functions before cAR4; both are expressed at a significantly higher level } \\
\text { in prestalk than prespore cells }\end{array}$ \\
\hline \multicolumn{2}{|l|}{ Spore } \\
\hline spiA & spore coat protein; induced at the onset of prespore $\rightarrow$ spore differentiation during culmination \\
\hline
\end{tabular}

This dilemma is solved by preferentially expressing essential components of the signaling pathway in the anterior region of the slug. cAR2 expression is induced at the mound stage and is preferentially expressed in prestalk cells. cAR2 is a very low-affinity receptor, suited to mediating oscillatory pathways when cAMP levels are high (Johnson et al. 1992). Another essential component needed for oscillator function is PDE, which is necessary to hydrolyze the extracellular cAMP. During the multicellular stages, PDE is preferentially expressed in the anterior prestalk A cells, in a location necessary to maximally reduce the cAMP levels in the tip (Hall et al. 1993).

One of the striking aspects of the spatial pattern within the slug is the sharp boundary between the prestalk and prespore regions in the absence of an extracellular matrix to form a barrier. In Dictyostelium, celltype differentiation is plastic, similar to the situation for cells in some metazoan embryos (Davidson 1986), but more extreme, with the prestalk and prespore cells not being fully committed to form stalk cells and spores until culmination. Prestalk cells can differentiate into stalk cells and vice versa under specific conditions, and cells can respond to changes in nutrient availability by reentering the cell cycle (Loomis 1982). Moreover, in studies in which prespore cells are precociously induced to form spores, new prespore cells arise from the remaining prestalk and ALC populations (Mann and Firtel 1993; Mann et al. 1994). During normal development, there is some back-and-forth movement between the prestalk, ALC, and prespore populations with limited dedifferentiation and redifferentiation, highlighting both the plasticity of the cells and the absence of a barrier between the prestalk and prespore zones (Abe et al. 1994). This overall plasticity allows organisms of varying sizes to have the same spatial patterning. The pathway that regulates the prestalk/prespore boundary is not known; however, cells lacking cAR4, which is expressed most strongly in the anterior prestalk cells, show a partial breakdown of the boundary and the presence of significant numbers of prespore cells in the anterior region (Louis et al. 1994).

\section{The role of the cell cycle in directing prestalk and prespore pathways}

A number of studies indicate that the position of a cell in the cell cycle at the time of starvation plays an important role in controlling the initial decision whether a cell differentiates into a prestalk or prespore cell. As in Schizosaccharomyces pombe, the cell cycle in Dictyostelium lacks a $G_{1}$ phase (Weijer et al. 1984a). Individual cells starved early in the cell cycle $\left(S\right.$ and early $G_{2}$ ) have a propensity to differentiate into prestalk cells, whereas cells starved later in $G_{2}$ tend to differentiate into prespore cells (Weijer et al. 1984b; Gomer and Firtel 1987; Maeda 1993; Araki et al. 1994). The prestalk/prespore ratio obtained using cell culture assays is similar to that 
found in the slug. However, synchronized early cells or late cells plated for development form normally proportioned aggregates, again highlighting the plasticity of Dictyostelium development. S- and early $\mathrm{G}_{2}$-phase cells have a higher concentration of many of the signaling components needed for aggregation and are the first to initiate cAMP pulsing within an unsynchronized population (McDonald 1986; Wang et al. 1988). Cells starved in late $G_{2}$ can also initiate cAMP signaling, but they require several additional hours of starvation before they initiate this process.

Differential transcriptional regulation of the signaling components during the cell cycle in vegetative cells might be the molecular mechanism for the initial determination of whether a cell differentiates into a prestalk or prespore cell. Gal, RasD, and the protein tyrosine phosphatase PTP2 affect aggregation-stage responses. They are expressed at low levels in vegetative cells and are preferentially expressed in a prestalk-enriched or ALC pattern during the multicellular stages (Esch and Firtel 1991; Howard et al. 1992, 1994; Dharmawardhane et al. 1994). Promoter/lacZ reporter studies of these genes show that only $\sim 10 \%-15 \%$ of the vegetative cells stain strongly at any one time. For rasD, in which expression has been examined in cell cycle-synchronized populations, the fraction of cells that stain changes throughout the cell cycle (Esch 1991). Approximately $50 \%$ of the cells stain early in the cell cycle, whereas the fraction decreases to $<5 \%$ for late $G_{2}$ cells. Thus, the level of one or more of these or other components as cells are starved may control the cell cycle effect on cell-type differentiation.

\section{The transcription factor GBF regulates the developmental switch from aggregation to cell-type differentiation}

A developmental switch from aggregation to cell-type differentiation is induced late during aggregation. As the mound forms, cAMP levels start to rise (Abe and Yanagisawa 1983). This inhibits the expression of the aggregation-stage, pulse-induced genes by adapting the pathways (see above) and activates a cascade that results in the induction of postaggregative and cell-type-specific genes, prestalk and prespore cell differentiation, and morphogenesis (Town and Gross 1978; Mehdy et al. 1983; Kimmel and Firtel 1991; Williams 1991; Schnitzler et al. 1994). This developmental switch is regulated by a change in the cAMP receptor-mediated signaling pathway from one that is regulated by nanomolar pulses of cAMP during aggregation to one that is controlled by a higher, more continuous cAMP signal within the mound (Schnitzler et al. 1995).

By activating expression of genes in cell culture assays in the absence of multicellular development, it is possible to identify essential regulatory molecules. The genes required for the multicellular stages of development can be divided into three major classes: postaggregative, prestalk, and prespore. Postaggregative genes are induced first within the developing mound and can be induced in suspension cultures of cells starved for $6 \mathrm{hr}$ in response to micromolar concentrations of extracellular cAMP in the absence of sustained cell-cell contact, contact with a substratum, or other signals (Mehdy and Firtel 1985; Schaap et al. 1986; Jermyn et al. 1987) (See Fig. 1). These genes include those required for morphogenesis and subsequent cell-type gene expression, such as the transcription factor GBF and the putative cell-surface regulatory protein $\mathrm{LagC}$, genes whose expression becomes enriched in the prestalk cells (prestalk-enriched genes, e.g., CP2 and $\operatorname{ras} D \mid$, and genes that are later preferentially expressed in ALCs (e.g., Go4 and PTP1) (Reymond et al. 1984; Pears et al. 1985; Datta et al. 1986; Hadwiger and Firtel 1992; Howard et al. 1992; Dynes et al. 1994). (See Tables 1 and 2 for the functions of these genes.) The prestalk (ecm $A$ and $e c m B)$ and prespore cell type-specific genes (Table 2 ) are induced $\sim 2 \mathrm{hr}$ after the postaggregative genes within the mound and require sustained cellcell or cell-substrate contact in some strains as well as prior exposure to high levels of cAMP (see above; Kimmel and Firtel 1991; Williams 1991). The cell-cell contact may help maintain appropriate levels of diffusable molecules such as the morphogen DIF (differentiatoninducing factor, a chlorinated hexaphenone) or may involve specific signaling pathways mediated by cell-surface molecules (Dynes et al. 1994). The temporal pattern of induction of the postaggregative and cell type-specific genes in cell culture mimics the temporal pattern of induction during multicellular development (see Fig. 1). When cAMP is given to cells starved for $6 \mathrm{hr}$, the gene encoding the transcription factor GBF is the first to be induced. GBF transcripts are maximal after $<1 \mathrm{hr}$ of cAMP stimulation, whereas transcripts for $C P 2$ and LagC reach maximal levels after $\sim 3-4 \mathrm{hr}$ and expression of ecm $A$ and the prespore gene $S P 60 / \operatorname{Cot} C$ is not detected until $4 \mathrm{hr}$ (Schnitzler et al. 1994, 1995). Removal of extracellular CAMP at any stage during induction results in a rapid deactivation of the genes (Mehdy et al. 1983; Hjorth et al. 1989).

It is the rise in extracellular cAMP in the mound, stimulating the activity of the transcription factor GBF, that is thought to activate postaggregative gene expression and initiate the transcriptional events leading to celltype-specific gene expression (Figs. 4 and 5B). A conserved regulatory element, designated a G-box or CAE, has been identified in postaggregative and cell-type-specific gene promoters (Datta and Firtel 1988; Pears and Williams 1988; Hjorth et al. 1989, 1990; Pavlovic et al. 1989; Haberstroh and Firtel 1990; Haberstroh et al. 1991; Ceccarelli et al. 1992; Esch et al. 1992; Fosnaugh and Loomis, 1993; Powell-Coffman and Firtel 1994). These elements are required for gene expression during multicellular development and responsiveness to cAMP in cell suspension assays and bind a developmentally regulated DNA-binding protein designated GBF (Hjorth et al. 1989, 1990; Haberstroh and Firtel 1990; Haberstroh et al. 1991). In vivo and in vitro studies indicate that GBF directly mediates the expression of these genes. Mutations in either of two G-box/CAE half-sites eliminate the ability to bind GBF in vitro and for the site to function in 


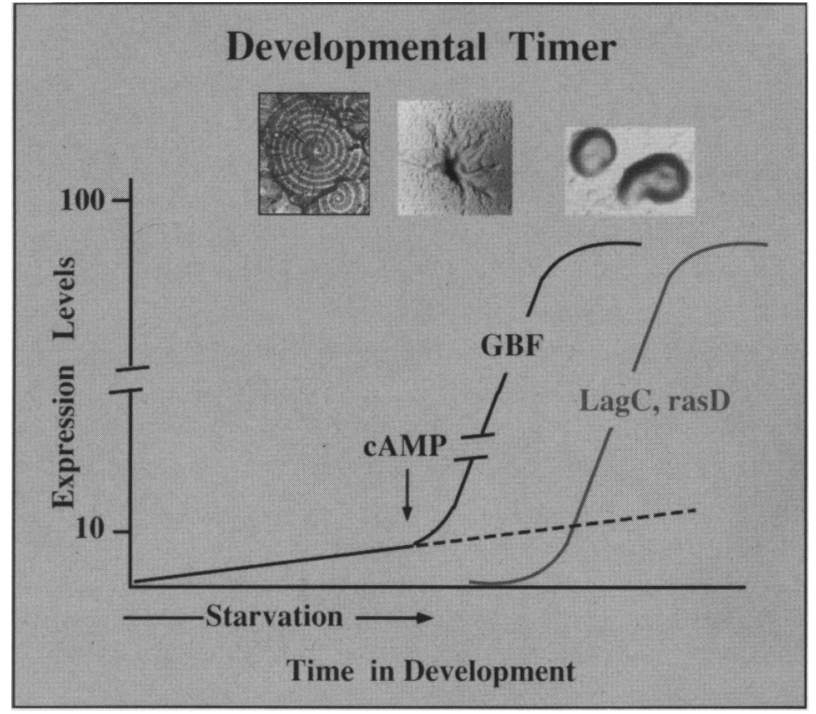

Figure 4. Regulation of GBF and postaggregative gene expression. GBF is expressed at low levels during growth, and the levels increase during early development. GBF expression and binding activity are induced to high levels as the mound forms and levels of intercellular cAMP increase or in response to exogenous cAMP, and they reach maximum levels very rapidly. Postaggregative genes, such as $\operatorname{Lag} C, C P 2$, and $r a s D$, are induced with a lag relative to GBF as GBF activity is required for their expression. In cells expressing GBF constitutively, postaggregative genes are rapidly induced with RNA being detected within $15 \mathrm{~min}$. (See text for details and references.)

vivo. In addition, the affinity of the element for GBF directly corresponds with the level of induction of the gene in the mound or in response to cAMP. G-boxes/ CAEs from prestalk-enriched and prespore-specific genes can be interchanged, indicating that the element does not confer cell-type specificity, only the ability to be expressed during multicellular development (Hjorth et al. 1990; Ceccarelli et al. 1992; Powell-Coffman 1994; Powell-Coffman et al. 1994). Cell-type-specific cis-acting regions have been identified for prestalk-enriched and prestalk- and prespore-specific genes that function in association with G-boxes to mediate the correct pattern of cell-type expression (Datta and Firtel 1988; Ceccarelli et al. 1991, 1992; Haberstroh et al. 1991; Early et al. 1993; Powell-Coffman et al. 1994). GBF contains two centrally located, putative zinc fingers with homology to the zinc finger in the glucocorticoid receptor (Schnitzler et al. 1994).

gbf null cells have a particularly interesting phenotype. They aggregate normally and form a mound, but no postaggregative genes are induced, and development arrests (Fig. 5A; Schnitzler et al. 1994). Pulse-induced genes are induced and then repressed normally as the mound forms and cAMP levels rise, which presumably adapts the aggregation-stage signaling pathways. Thus, the repression of aggregation-stage events is mediated by the rise in CAMP in the mound and not the result of postaggregative gene expression. In this regard, the for- mation of the mound functions as a developmental timer to induce postaggregative genes and repress aggregationstage processes. The $g b f$ null mutant thus effectively dissociates aggregation-stage and postaggregative stage development. The inhibition of pulse-induced genes in the mound can be mimicked in vitro by providing high, continuous cAMP to cells that have been induced previously by 30 nм cAMP pulses (Mann and Firtel 1989; Schnitzler et al. 1995). Interestingly, in gbf null cells, the newly formed mound then dissipates, presumably because it cannot undergo further morphogenesis and because the dynamic chemotactic pathways that originally formed the mound are repressed (Fig. 5A,B). As the mound dissipates, the pulse-induced genes are reinduced, presumably because of the decrease in extracellular cAMP levels as the mound falls apart and a resultant deadaption of the aggregation-stage pathways. The cells then reaggregate to form a new mound, and the cycle repeats.

$g b f$ null cells constitutively expressing GBF do not express the other postaggregative genes until formation of the mound, indicating that GBF is not sufficient to induce late genes (Schnitzler et al. 1994, 1995). However, when washed complemented $g b f$ null vegetative cells are provided CAMP, the postaggregative genes are rapidly induced (Schnitzler et al. 1995). This indicates that a cAMP-mediated pathway, in addition to GBF, is required to induce late gene expression and that the signal transduction pathway necessary for inducing late genes is already present in vegetative cells. Why cannot high cAMP levels induce $G B F$ and downstream genes in early wildtype cells? A type of built-in timing mechanism appears to prevent this. Wild-type vegetative cells have insufficient levels of GBF to activate this pathway. GBF expression is very low in vegetative cells and increases to a low level in response to starvation. When GBF levels are sufficient, GBF expression can be rapidly induced, either as the mound forms or in response to high cAMP levels (Fig. 4; Schnitzler et al. 1994, 1995). Consistent with this model, studies have suggested that GBF regulates its own expression, but definitive proof awaits analysis of the GBF promoter (Hjorth et al. 1989; Schnitzler et al. 1994). Also as predicted, the cell type-specific genes are not induced until cells enter the mound and respond to the high cAMP level, although they are competent to respond to CAMP in suspension culture several hours earlier. In cells constitutively expressing GBF, other postaggregative genes are induced very rapidly in response to CAMP, with levels of transcript reaching near maximal levels within $1 \mathrm{hr}$ after stimulation. ecmA and SP60 are also induced but only after several hours of exposure to CAMP, implying that there are genes downstream from GBF whose products are necessary for the induction of these genes (see below; Fig. 6).

\section{Two independent signaling pathways regulate aggregation and postaggregative development}

The above analysis suggests that two distinct signaling pathways, one responding to cAMP pulses and one to a higher, continuous level of cAMP, differentially regulate 


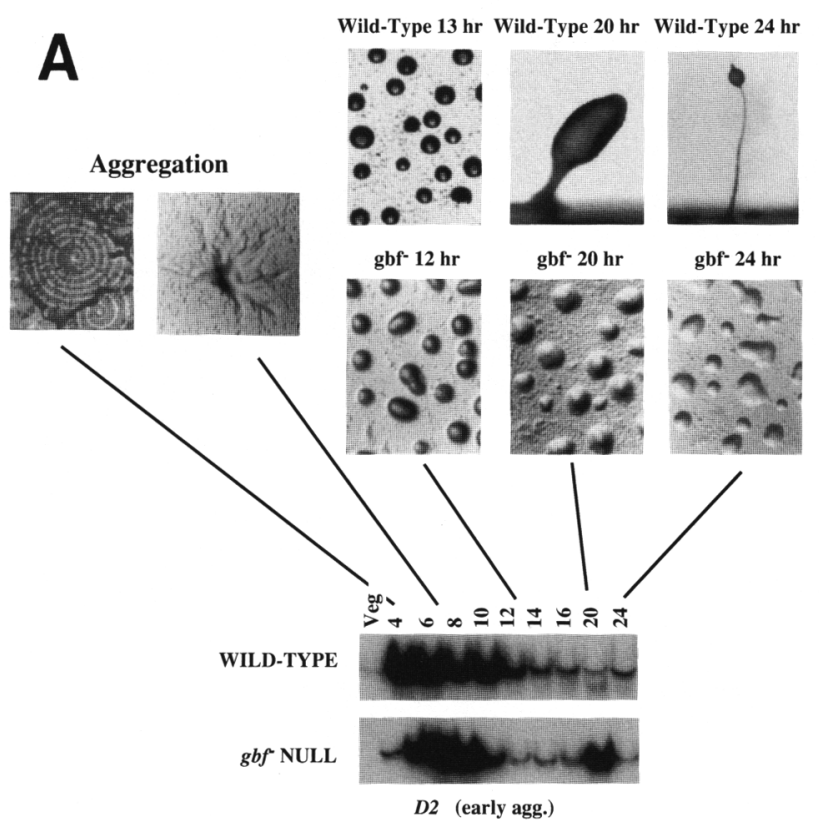

B

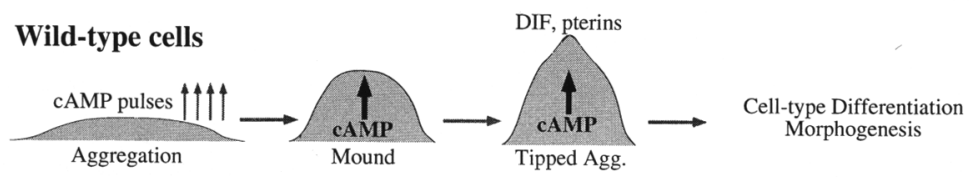

$g_{\alpha} 2$ null cells

No cAMP pulses

No Aggregation

g $\alpha 2$ null cells plus high cAMP
Shake cells in buffer
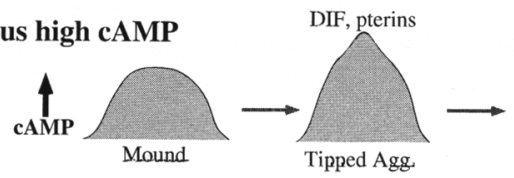

Cell-type Differentiation Morphogenesis gbf null cells
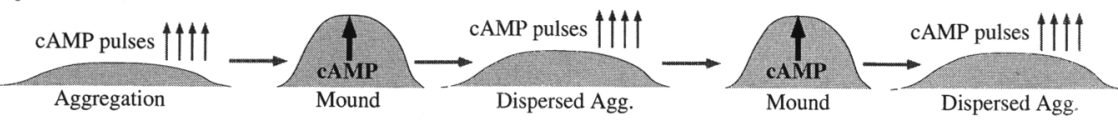

Figure 5. Morphology and molecular phenotype of $g b f$ null cells. $(A)$ Developmental morphology of wild-type and $g b f$ null cells. At $12 \mathrm{hr}$, gbf null cells have formed aggregates, and essentially all cells are in aggregates. At $20 \mathrm{hr}$, many of the cells have separated from the aggregates, which are flatter and more spread out. At $24 \mathrm{hr}$, they have reformed. The developmental expression of a pulse-induced gene (D2) is shown. In wild-type cells, its expression is induced during aggregation and repressed with mound formation. In gbf null cells, it is induced and repressed normally but then gets reinduced as the mounds have dissipated and re-repressed as the mounds reform. (B) A shift between cAMP pulses and continuous, high levels of cAMP within the aggregate mediates the developmental switch between aggregation and cellular differentiation. Cartoon of morphology and developmental signals in wild-type cells, $g \alpha 2$ null cells with and without cAMP, and $g b f$ null cells (see text for details). A shift between cAMP pulses and continuous, high levels of CAMP within the aggregate mediates the developmental switch between aggregation and cellular differentation. $g \alpha 2$ null cells will induce late genes if starved for $6 \mathrm{hr}$ and then given high, continuous cAMP. If, after $12 \mathrm{hr}$, the cells are plated on agar, small fruiting bodies with mature spores are obtained. The fruiting bodies are abnormal, because of the absence of proper cAMP signaling in the absence of a $\mathrm{G} \alpha$-subunit to couple to the cARs (cAR4). This is also consistent with the abnormal culminants produced when a dominant-negative G $\alpha 2$-subunit is expressed in prestalk cells. aggregation and postaggregative development and celltype differentiation. Earlier pharmacological studies suggested that the same cAMP receptors /or receptors with the same ligand-binding specificities) control aggregation and postaggregative development (Schaap and Van Driel 1985; Gomer et al. 1986a; Haribabu and Dottin 1986; Oyama and Blumberg 1986). The differences between the aggregation-stage and postaggregative pathways were uncovered when the ability of cAMP to induce postaggregative genes was examined in various $\mathrm{mu}$ tant strains constitutively expressing GBF (Schnitzler et al. 1995). Studies using deletion mutants of cARl and cAR3 showed that either is essential, indicating that the same receptors regulate aggregation and postaggregative gene expression. Unexpectedly, postaggregative genes are induced normally in cells expressing GBF but lacking either $\mathrm{G} \alpha 2$, which couples to cARs, or the sole known G $\beta$-subunit, both of which are required for aggregation (Schnitzler et al. 1995). Studies of the biochemical properties of the $g \beta$ null cells strongly suggest that there is only a single G $\beta$ subunit in Dictyostelium (Wu et al. 1995 |, although one cannot exclude a G $\beta$ subunit that is expressed at very low levels or has unusual biochemical properties. This suggests that $\mathrm{cAMP}$ receptor activation of postaggregative gene expression mediated by GBF functions through a signaling cascade that does not require a coupled $G$ protein, a previously undefined pathway by which seven transmembrane receptors might signal. This pathway is outlined in Figure 2. Although G proteins do not appear to be required for receptor activa- 
Figure 6. Model of signaling to control cell-type differentiation. (A) Model of the signaling pathways. A low level of GBF is expressed during starvation. As the mound forms, cAMP levels rise, which activates GBF and downstream gene expression (postaggregative genes) through a cAMP receptor-mediated signaling pathway that may involve the post-translational modification of GBF or an associated protein. This induces the postaggregative genes, including $\operatorname{LagC}$, which is essential for celltype-specific gene expression. LagC may be involved in cell-cell contacts that promote prestalk/prespore gene expression. It may feed back to enhance GBF function and the expression of other primary genes, facilitating the activation of prestalk and prespore genes. DIF is required for the prestalk pathway and inhibits the prespore pathway. GSK-3 is required for prespore gene expression. In gsk-3 null cells, essentially all cells differentiate into prestalk cells. "Folate" refers to the requirement of $\mathrm{G} \alpha 4$, which couples to folate/pterin receptors and is required for prespore/spore differentiation. (B) DIF is required both for prestalk $\mathrm{A} / \mathrm{O}(\mathrm{ecm} A)$ and prestalk $\mathrm{B}(e \mathrm{~cm} B)$ induction. cAMP enhances $e c m A$ and represses $e c m B$. Models of $\mathrm{cAMP}$ oscillations within the slug suggest that the prestalk B cells are localized in a region of low cAMP levels. The geometry of the oscillator may control the spatial localization of prestalk A/O and prestalk B cells within the anterior region. (See text for details and references.)

tion of the postaggregative genes such as $\operatorname{Lag} C$, ras $D$, and $C P 2, \mathrm{G} \beta$ is required for the subsequent induction of the cell-type-specific genes, consistent with the observation that the level of prespore and prestalk gene expression is reduced in go4 null cells (Hadwiger and Firtel 1992; Schnitzler et al. 1995). Other studies show that cAMP also activates a $\mathrm{Ca}^{2+}$ influx by a pathway that, by the same criteria, is G protein-independent (Milne et al. 1995).

The independence of the pathways controlling aggregation and cell-type differentiation is highlighted by several studies. As described above, $\mathrm{G} \alpha 2$ is required for mediating signal transduction events essential for in vivo aggregation, and no other $\mathrm{G} \alpha$ subunit has been found to substitute for $\mathrm{G} \alpha 2$ (Wu et al. 1994a,b). When 6-hr starved ga2 null cells (not expressing GBF constitutively) are given high levels of CAMP, postaggregative and cell-typespecific genes are induced with kinetics similar to wildtype cells (Schnitzler et al. 1995). When these cells are then placed on agar, small agglomerates form that differentiate into fruiting bodies (Fig. 5B). Although the morphology is not fully wild-type, mature spores are formed. Consistent with the induction of postaggregative development being Ga2 independent, expression of a dominant-negative form of G $\alpha 2$ blocks cAMP-mediated responses when expressed during aggregation but has no effect on cell-type differentiation when expressed from either a prestalk- or prespore-specific promoter, although expression from the prestalk promoter does lead to abnormalities in stalk morphogenesis during culmination (Carrel et al. 1994).

The identification of potentially $G$ protein-independent pathways regulated by seven-span receptors is novel, although evidence for such pathways in other systems does exist. A G protein-independent response has been reported for yeast in response to pheromone (Jackson et al. 1991). In mammalian cells, the binding and phosphorylation of both the $\beta$-adrenergic receptor and rhodopsin by their respective kinases requires activation by ligand binding or light, respectively, but is independent of heterotrimeric $G$ proteins (Palczewski et al. 1991; Chen et al. 1993). In addition, it has been suggested that the angiotensin II receptor may function via a G protein-independent pathway (Kambayashi et al. 1993; Mukoyama et al. 1993), although no such definitive pathways have been identified. We expect that more extensive $G$ protein-independent pathways exist in higher organisms but may not have been identified because of the the inability to use extensive genetic manipulation or the absence of the necessary assays. The recent identification of previously unknown seven-span receptormediated pathways in mammalian cells, such as the activation of PI3 kinase (Stephens et al. 1994), suggests that the identification of all pathways may be far from complete.

Requirements for cell-type-specific gene expression: cell-cell interactions and the DIF morphogen

In addition to high cAMP levels, cell-cell interactions or cell-substrate interactions and products of the postaggregative genes are essential to induce the prestalk- and prespore-specific late genes, as described above. One gene required for cell-type-specific gene expression is LagC, which encodes a putative cell-surface signaling protein with a predicted single transmembrane domain and a long extracellular domain (Dynes et al. 1994). LagC lies downstream from GBF and requires both GBF and cAMP for expression. Like $g b f$ null cells, $1 a g C$ null cells form mounds that dissipate and re-form with development arresting at this stage. $\operatorname{lag} C$ null cells express the other primary postaggregative genes $(C P 2$ and rasD) in vivo or in response to cAMP (although at low levels) but not the cell-type-specific genes. LagC functions cell 
nonautonomously, as $\operatorname{lag} C$ null/wild-type cell chimeras develop normally and cell-type-specific genes are induced in the $\log C$ null cells. The putative structure of $\mathrm{LagC}$ as a cell-surface protein is consistent with its proposed function as a signaling molecule in cell-cell interactions. These results suggest that cAMP activates GBF expression, which then induces the expression of LagC, which in turn mediates a process that is required for celltype-specific gene expression and cell-type differentiation. LagC does not appear to function as a cell adhesion molecule per se because overexpression of $\mathrm{LagC}$ does not cause apparent increased cell adhesion. Although the mechanism by which LagC functions is not known, it may function, in part, as a feedback stimulator of GBF expression, which is lower in $\operatorname{lag} C$ null cells than in wild-type cells (Fig. 6).

The morphogen DIF induces single cells to differentiate into stalk cells in monolayer culture and is essential for the induction of $e \mathrm{~cm} A$ and $e \mathrm{~cm} B$ and for prestalk/ stalk cell differentiation (Town et al. 1976; Berks et al. 1991; Williams 1991). Extracellular cAMP is necessary to achieve sufficient developmental competence for prestalk cell differentiation through the GBF pathway. However, late in the process of cell-type differentiation, DIF and cAMP are antagonists in the expression of $e \mathrm{cmB}$ (DIF induces; cAMP represses). For ecmA, cAMP stimulates DIF-dependent expression. For prespore genes, cAMP induces expression, whereas DIF inhibits expression (Early and Williams 1988). The mechanism by which DIF regulates gene expression is not known; however, a cytosolic binding protein has been identified (Insall and Kay 1990).

Among the unsolved questions are, How do cells respond differentially to the DIF present in the developing mound? and What is the mechanism by which DIF functions? In the whole organism, DIF induces only a small percentage of cells to become prestalk cells. Thus, how do the remaining cells differentiate into prespore cells in the presence of DIF? It is possible that cells with a propensity to become prestalk cells (cells starved earlier in the cell cycle) are more sensitive to DIF and may induce a positive feedback pathway that increases their sensitivity to reduced levels of DIF. Prestalk B cells, which require DIF for their induction, have been reported to synthesize high levels of DIF in vitro (Kwong et al. 1990). In addition, the developing prestalk cells may act as a sink for the morphogen, reducing the overall concentration within the mound (Insall et al. 1992; Kay et al. 1993). Consistent with this idea, prestalk cells have a higher concentration of the enzymes required to metabolize and inactivate DIF than prespore cells. These enzymes are induced by DIF, providing a feedback loop (Insall et al. 1992). In the slug, DIF is present in the posterior at a higher concentration than in the tip, possibly as a result of a higher rate of metabolism in the prestalk cells (Brookman et al. 1987). The function of DIF in the prespore zone, if any, is unknown. It may be involved in maintaining the differentiated state of ALCs and/or in modulating prespore gene expression (see below).
GSK-3, PKA, and other regulatory molecules controlling cell fate

What other components are required for cell-type differentiation? What components regulate the prestalk/prespore ratio? It is now clear that these pathways are complex and involve PKA and GSK-3, which also control cell-fate decisions in Drosophila. In Drosophila, GSK-3, the product of the shaggy/zest-white 3 locus, is required for multiple cell-fate decisions during embryogenesis and is thought to function downstream from wingless (Siegfried et al. 1990, 1992; Simpson et al. 1993). In Dictyostelium, GSK-3 plays a crucial role in the decisionmaking process between prestalk and prespore cell pathways (see model in Fig. 6). GSK-3 is required for prespore differentiation as gsk-3 null cells differentiate to yield a high percentage of ecmB-expressing prestalk cells, whereas prespore cell differentiation is minimal (Harwood et al. 1995).

GSK-3 regulation of prespore/prestalk cell-fate determination may involve pathways controlled through the cAMP receptors cAR2 and cAR4. In wild-type cells, extracellular cAMP inhibits differentiation of the prestalk $B$ cells once the pathways are initiated by the induction of GBF. However, this does not occur in gsk-3 null cells. This, plus the lack of prespore gene expression in $g s k-3$ null cells, suggests that GSK-3 functions to activate the prespore pathway and repress the prestalk $B$ pathway in response to CAMP. This phenotype is the opposite of that seen in car2 or car4 null cells (Saxe et al. 1993; Louis et al. 1994). This suggests that CAR2 and cAR4, which are preferentially expressed in prestalk cells, may function to inhibit GSK-3 function and suppress prespore differentiation. cAR2 and cAR4 may function through the production of a diffusible substance, produced in the anterior, prestalk region that would act to repress prespore gene expression and help establish the prestalk/prespore boundary by negatively regulating GSK-3 function (Harwood et al. 1995). Alternatively, cAR2 and cAR4 may negatively regulate GSK-3 via a cell-autonomous pathway within prestalk cells. The spatial pattern of GSK-3 expression is not yet known; however, because it is expressed throughout growth and development, it may be present in all cells.

The heterotrimeric $G$ protein $\alpha$-subunit $G \alpha 1$ (see below) and PKA are also involved in prestalk $A B$ cell differentiation. PKA, which has been shown recently to be important in cell-fate determination in Drosophila (Perrimon 1995), is thought to regulate a repressor element in the ecmB promoter (Ceccarelli et al. 1991; Harwood et al. 1993). Removal or mutation of this element expands $e c m B$ expression into the entire anterior prestalk region. The ability of the repressor to inhibit ecm $B$ expression in prestalk A cells is negatively regulated by PKA (Harwood et al. 1993; Williams et al. 1993a). In gsk-3 null cells, the inhibition of $e \mathrm{cmB}$ expression by extracellular cAMP is lacking, suggesting that GSK-3 and PKA may be a component of the same pathway. Interestingly, PKAcat expression is high in the very anterior of the slug in prestalk $A$ and $A B$ cells (Mann et al. 1994). PKA is also 
required cell autonomously for the initial induction of both the prestalk and prespore pathways (Mann and Firtel 1991; Williams et al. 1993b). The heterotrimeric G $\alpha$ subunit $G \alpha 1$ appears to function as a negative regulator of prestalk $A B$ differentiation and morphogenesis. $G \alpha 1$ and $e \mathrm{~cm} B$ have indistinguishable patterns of expression, and expression of a dominant activating $G \alpha 1$ subunit from the $\mathrm{G} \alpha 1$ promoter results in a loss of $e \mathrm{~cm} B$ expression in the anterior core of prestalk $A B$ cells and abnormal slug morphogenesis and culmination (Dharmawardhane et al. 1994).

Increases in intracellular $\mathrm{Ca}^{2+}$ have been implicated in the induction and maintenance of the prestalk pathway. Prestalk cells are known to sequester $\mathrm{Ca}^{2+}$ and have higher cytosolic levels of $\mathrm{Ca}^{2+}$ (Maeda and Maeda 1973; Tirlapur et al. 1991; Schlatterer et al. 1992; Cubitt et al. 1995). Artificially increasing the cytosolic $\mathrm{Ca}^{2+}$ levels using thapsigargin and $\mathrm{Ca}^{2+}$ ionophore causes a significant increase in the percentage of cells that finally differentiate into stalk cells, at the expense of spore cells (Kubohara and Okamoto 1994). Although modulation of the level of $\mathrm{Ca}^{2+}$ appears to affect the ratio of prestalk and prespore cells, it is unclear whether $\mathrm{Ca}^{2+}$ functions as a "determinant" to promote some cells to become prestalk cells. Other gene products required for prestalk or prespore cell-type differentiation are being identified in a number of laboratories using REMI insertional mutagenesis; thus, the complexity of these pathways is expected to increase significantly in the near future.

\section{ALCs serve as essential regulatory components}

ALCs fate map to the lower cup of the sorus and the basal disc, as opposed to the anterior prestalk cells, which predominantly form the stalk (Jermyn and Williams 1991). When posterior, prespore regions are dissected from the whole slug, the ALCs form a new tip and new ALCs are recruited from the prespore population (Sternfeld and David 1982). Recent studies suggest that these cells also have a regulatory role within the slug. A number of regulatory gene products have been shown to be preferentially expressed in ALCs during the multicellular stages, with little or no expression in prestalk or prespore cells. These include the MAP kinase ERK1, two protein-tyrosine phosphatases (PTP1 and PTP2), and Ga4 (Howard et al. 1992, 1994; Gaskins et al. 1994; Hadwiger et al. 1994).

The strongest evidence for a cell nonautonomous role of ALCs in controlling developmental decisions is provided by studies on the heterotrimeric $G \alpha$ subunit $G \alpha 4$, whose expression during the multicellular stages requires induction by cAMP. ga 4 null cells arrest at the first finger stage and express prespore genes at very low levels (Hadwiger and Firtel 1992). Furthermore, spore production in ga 4 null cells is reduced approximately four orders of magnitude. When these cells are mixed with wild-type cells, normal-appearing fruiting bodies are formed and there is a partial complementation of the spore production defect in the ga 4 null cells. These and other studies suggest that G $\alpha 4$ functions in ALCs to reg- ulate differentiation of adjacent prespore cells. G $\alpha 4$ does not couple to cAMP receptors but couples to at least two classes of receptors that bind folate and other pterins [folic acid receptors (FARs)] (Hadwiger et al. 1994), although G $\alpha 4$ may also couple to a receptor for an unknown ligand. These results suggest that this or another pterin functions as an essential signaling molecule during the multicellular stages. Dictyostelium cells produce a pterin with a structure similar to a pterin that can activate G $\alpha 4$-dependent pathways during the multicellular stages, which may be the molecule mediating $\mathrm{G} \alpha 4$ pathways (Klein et al. 1990; Hadwiger et al. 1994).

\section{Culmination-regulation by PKA and other signaling pathways}

Slugs migrate phototactically to directional light until the environment is optimal for fruiting body formation (Loomis 1975). During this time, the spatial patterning of the slug remains constant and little differentiation into stalk and spores takes place. High $\mathrm{NH}_{4}{ }^{+}$and humidity in the absence of overhead light inhibits culmination. Viewed teleologically, this allows the slug to migrate from beneath decaying leaves on the forest floor before culminating to optimize dispersion of the spores. Under laboratory conditions, migrating slugs stop immediately when exposed to overhead light and initiate culmination. Prestalk A cells enter a cone formed at the top of the stalk tube, induce a stalk cell-specific component of the ecmB promoter, and differentiate into stalk cells (Williams et al. 1993b). The forming stalk tube elongates through the prespore mass, lifting it off the substratum. Simultaneously, the ALC population migrates to form the basal disc and the upper and lower cups of the maturing sorus. The analysis of mutants that affect $\mathrm{G} \alpha 2$, cAR4, and PDE all point to the morphogenetic movements being controlled by extracellular cAMP and receptor/Ga2-mediated pathways (Okaichi et al. 1992; Hall et al. 1993; Louis et al. 1994).

Midway through formation of the stalk tube, prespore cells begin to differentiate into spore cells. spiA is not expressed until prespore cells begin terminal differentiation and is a marker for spore cell differentiation (Richardson et al. 1991). spiA/lac Z staining initiates at the top of the sorus and proceeds toward the base, indicating a gradient of prespore $\rightarrow$ spore differentiation (Richardson et al. 1994). Several findings suggest that PKA activation triggers this induction. First, strains expressing a dominant-negative PKA-R subunit from a prespore promoter produce fruiting bodies that contain undifferentiated amoebae in the sorus (Hopper et al. 1993b). Second, strains that lack a functional PKA-R subunit or express PKAcat from a prespore promoter develop rapidly and form spores precociously (Simon et al. 1992; Mann and Firtel 1993; Mann et al. 1994). Finally, spiA expression and spore cell differentiation can be induced in disaggregated slug cells by 8-Br-cAMP (Kay 1989; Riley et al. 1989; Richardson et al. 1991, 1994). In addition, similar experiments suggest that PKA regulates stalk cell differ- 
entiation independently (Harwood et al. 1992; Hopper et al. 1993a; Williams et al. 1993a).

The in vivo mechanism of PKA activation is not known. One might assume the activation is through an increase in intracellular cAMP, which is known to accompany culmination. However, cells lacking the $A C A$ gene, and thus in theory unable to make cAMP, can be coaxed into making abnormal fruiting bodies with spores if given CAMP analogs that are specific for cell-surface receptors (Pitt et al. 1993). Whereas the increase in PKA activity may be regulated by increases in intracellular cAMP, the results in the aca null cells suggest that other pathways may used in vivo. Ammonia, which blocks culmination, may inhibit PKA activation, possibly by blocking the increase in intracellular cAMP, or it may inhibit a downstream pathway (Wang and Schaap 1989; Davies et al. 1993; Hopper et al. 1993b; Gee et al. 1994). Recent evidence suggests that $\mathrm{NH}_{4}{ }^{+}$may regulate the $\mathrm{pH}$ of a cytosolic vacuolar compartment, which has been proposed to control, directly or indirectly, the activation of AC (Gross et al. 1983, 1988; Davies et al. 1993). In the maturing fruiting body, the PKAcat gene is preferentially expressed in the maturing spore cells, perhaps to a level that oversaturates the PKA regulatory subunits (Mann et al. 1994).

Biochemical analysis has identified a rapid rise in the potential second messenger 1,2-diacylglycerol (DG) that occurs at the onset of culmination, and elevated DG levels are maintained throughout the time of stalk cell differentiation (Cubitt et al. 1993). This increase in DG, which probably results from the activation of PLD and not PLC, may be involved in regulating the induction of culmination. DG levels are induced to maximal levels within $2 \mathrm{~min}$ in slugs in response to overhead light, which induces culmination. The extent of the increase in DG levels depends on the level of $\mathrm{G} \alpha \mathrm{l}$, which plays an important role in culmination (Dharmawardhane et al. 1994). Mutants (sluggers) that show extended slug migration and delayed culmination are hypersensitive to $\mathrm{NH}_{4}{ }^{+}$(Gee et al. 1994), as are strains expressing the dominant-negative PKA-R from a prespore promoter. It is possible that $\mathrm{NH}_{4}{ }^{+}$could be affecting multiple pathways, including the PKA pathway and that leading to DG production.

\section{Developmental themes, insights, and the future}

The analysis of signaling pathways in Dictyostelium has led to new insights into how organisms solve common developmental problems and an understanding of the underlying molecular mechanisms. The Dictyostelium developmental program, like that of metazoans, is separated into two major phases: the formation of the multicellular organism and cell-type differentiation and morphogenesis. Whereas metazoans form a multicellular organism through the division of the zygote, the multicellular organism in Dictyostelium is formed through the coaggregation of independent cells, using $G$ proteincoupled signaling pathways that are similar to those used to mediate chemotaxis in neutrophils and that in- volve both the activation of downstream effectors and a requisite period of adaptation. The analysis of the pathways leading to aggregation and the developmental switch between the formation of the multicellular organism and its subsequent differentiation has yielded new concepts about how receptors perceive ligands: The pulsatile signal that controls aggregation and the continuous CAMP signal that controls multicellular differentiation activate distinct signaling pathways from the same receptors. Although many of the pathways leading to aggregation are regulated through classic $\mathrm{G}$ protein-coupled pathways, the activation of GBF function is mediated through distinct pathways that may be G proteinindependent. Developmental timing is solved by making use of these cAMP-mediated pathways. During aggregation, cells have the ability to respond to either a pulsatile or continuous signal. The formation of the mound, which results in an elevation of the levels of CAMP, initiates the developmental switch in signaling pathways by repressing aggregation-stage pathways and activating GBF function. Not unexpectedly, downstream cell-type differentiation uses cell-cell interactions and signaling molecules such as GSK-3 and PKA, now known to regulate cell-fate decisions in metazoans. The more complex patterning of the multicellular organism and the orchestration of cell movements are mediated through a series of other signaling pathways, some of which use heterotrimeric $\mathrm{G}$ proteins as key regulatory molecules. Others use morphogens such as DIF and $\mathrm{NH}_{4}{ }^{+}$which most likely function through yet other molecular mechanisms.

In Dictyostelium, many of the developmental decisions are controlled by seven-span/serpentine receptors that couple to heterotrimeric $G$ protein-dependent, and possibly independent, pathways. In metazoans, significant attention has been given to both tyrosine kinase and transforming growth factor- $\beta$ (TGF $\beta$ ) cell-surface receptors as regulators of cell-fate decisions (Jessell and Melton 1992; Van der Geer et al. 1994). The importance of tyrosine phosphorylation in Dictyostelium is highlighted by the developmental function of at least three spatially and temporally regulated protein-tyrosine phosphatases (Howard et al. 1992, 1994) that are known to play an important role in various stages of Dictyostelium development as well as in controlling responses of starved cells to growth stimulation (Howard et al. 1993). Two tyrosine kinases have been identified in Dictyostelium, but these are probably not cell-surface receptors (Tan and Spudich 1990).

In both Dictyostelium and metazoans, the specificity of the signaling pathways is controlled by a combination of the spatial/temporal expression of both receptors and ligands plus the coupled intracellular signaling pathways. The emphasis on how $G$ protein-coupled pathways control development in Dictyostelium may be a function of early studies showing the importance of cAMPregulated pathways, which led to the identification and cloning of genes encoding CAMP receptors and eight distinct $G \alpha$ subunits. It is expected that REMI insertional mutagenesis will identify other receptors and signaling 
pathways, including those regulated by tyrosine phosphorylation. It is also anticipated that further analysis of $G$ protein-coupled pathways in metazoans will uncover their importance in controlling developmental events. The presence in Dictyostelium of at least two MAP kinases with specific developmental functions (Gaskins et al. 1994; Segall et al. 1995) suggests that additional signaling pathways remain to be elucidated.

The ability to dissect pathways using a combination of genetic, molecular, and biochemical approaches in Dictyostelium should allow rapid progress in coupling these mutants into defined biochemical pathways that regulate development in this system. Moreover, this should result in new insights into the control of signaling pathways common to all eukaryotes. The history of the analysis of yeast, Drosophila, and Caenorbhabditis elegans indicates that much can be learned about basic cellular decisions by studying a variety of systems that have powerful genetic, molecular, and biochemical tools. Examination of the cytoskeleton and myosin function in Dictyostelium has led to major insights into the mechanisms by which molecular motors work and into the role of the cytoskeleton in all eukaryotes. The insights into $\mathrm{G}$ protein-coupled pathways and activation of $\mathrm{AC}$ and chemotaxis, the identification of a molecular function for GSK-3, and the understanding of receptor activation of GBF should be directly applicable to all eukaryotes. The rapidity with which gene function can be examined in Dictyostelium should facilitate our understanding of many of the presently described pathways as well as identify pathways that may pioneer studies in other systems.

\section{Acknowledgments}

I thank Celia Briscoe, Jason Brown, Peter Devreotes, Marianne Gamper, Tony Hunter, Michael Levine, Richard Kessin, Alan Kimmel, Sandy Mann, Jim Posakony, Jennifer Roth, and Jeff Williams for critically reading this review and/or for helpful suggestions. This was supported by grants from the U.S. Public Health Service (to R.A.F.).

The publication costs of this article were defrayed in part by payment of page charges. This article must therefore be hereby marked "advertisement" in accordance with 18 USC section 1734 solely to indicate this fact.

\section{References}

Abe, K. and K. Yanagisawa. 1983. A new class of rapid developing mutants in Dictyostelium discoideum: Implications for cyclic AMP metabolism and cell differentiation. Dev. Biol. 95: 200-210.

Abe, T., A. Early, F. Siegert, C. Weijer, and J. Williams. 1994. Patterns of cell movement within the Dictyostelium slug revealed by cell type-specific, surface labeling of living cells. Cell 77: 687-689.

Araki, T., H. Nakao, I. Takeuchi, and Y. Maeda. 1994. Cellcycle-dependent sorting in the development of Dictyostelium cells. Dev. Biol. 162: 221-228.

Berks, M., D. Traynor, I. Carrin, R.H. Insall, and R.R. Kay. 1991. Diffusible signal molecules controlling cell differentiation and patterning in Dictyostelium. Development (Suppl.) 1: $131-139$.

Blumer, K. and G. Johnson. 1994. Diversity in function and regulation of MAP kinase pathways. Trends Biochem. Sci. 19: $236-240$.

Brookman, J.J., K.A. Jermyn, and R.R. Kay. 1987. Nature and distribution of the morphogen DIF in the Dictyostelium slug. Development 100: 119-124.

Buhl, B., K. Fischer, and H.K. Macwilliams. 1993. Cell sorting within the prespore zone of Dictyostelium discoideum. Dev. Biol. 156: 481-489.

Carrel, F., S. Dharmawardhane, A.M. Clark, J.A. Powell-Coffman, and R.A. Firtel. 1994. Spatial and temporal expression of the Dictyostelium discoideum $\mathrm{G} \alpha$ protein subunit $\mathrm{G} \alpha 2$ : Expression of a dominant negative protein inhibits proper prestalk to stalk differentiation. Mol. Biol. Cell 5: 7-16.

Ceccarelli, A., H. Mahbubani, and J.G. Williams. 1991. Positively and negatively acting signals regulating stalk cell and anterior-like cell differentiation in Dictyostelium. Cell 65: 983-989.

Ceccarelli, A., H.J. Mahbubani, R. Insall, G. Schnitzler, R.A. Firtel, and J.G. Williams. 1992. A G-rich sequence element common to Dictyostelium genes which differ radically in their patterns of expression. Dev. Biol. 152: 188-193.

Chen, C.-Y., S.B. Dion, C.M. Kim, and J.L. Benovic. 1993. Betaadrenergic receptor kinase: Agonist-dependent receptor binding promotes kinase activation. I. Biol. Chem. 268: 7825-7831.

Cubitt, A.B., S. Dharmawardhane, and R.A. Firtel. 1993. Developmentally regulated changes in 1,2-diacylglycerol in Dictyostelium: Regulation by light and G-proteins. I. Biol. Chem. 268: 17431-17439.

Cubitt, A.B., R.A. Firtel, G. Fischer, L. Jaffe, E. Karplus, and A.L. Miller. 1995. Patterns of free calcium in multicellular stages of Dictyostelium expressing jellyfish apoaequorin. Development (in press).

Datta, S. and R.A. Firtel. 1988. An 80-bp cis-acting regulatory region controls cAMP and development regulation of a prestalk gene in Dictyostelium. Genes \& Dev. 2: 294-304.

Datta, S., R.H. Gomer, and R.A. Firtel. 1986. Spatial and temporal regulation of a foreign gene by a prestalk-specific promotor in transformed Dictyostelium discoideum. Mol. Cell. Biol. 6: 811-820.

Davidson, E. 1986. Gene activity in early development, 3rd ed. Academic Press, New York.

Davies, L., M. Satre, J.B. Martin, and J.D. Gross. 1993. The target of ammonia action in Dictyostelium. Cell 75: 321-327.

Davis, R. 1993. The mitogen-activated protein kinase signal transduction pathway. I. Biol. Chem. 268: 14553-14556.

Devreotes, P.N. 1994. G protein-linked signaling pathways control the developmental program of Dictyostelium. Neuron 12: 235-241.

Devreotes, P.N. and S.H. Zigmond. 1988. Chemotaxis in eukaryotic cells: A focus on leucocytes and Dictyostelium. Annu. Rev. Cell Biol. 4: 649-686.

Dharmawardhane, S., A. Cubitt, and R. Firtel. 1994. Regulatory role of $\mathrm{G} \alpha 1$ subunit in controlling cellular morphogenesis in Dictyostelium. Development 120: 3549-3561.

Dingermann, T., N. Reindl, H. Werner, M. Hildebrandt, W. Nellen, A. Harwood, J. Williams, and K. Nerke. 1989. Optimization and in situ detection of Escherichia coli $\beta$-galactosidase gene expression in Dictyostelium discoideum. Gene 85: 353-362.

Drayer, A.L., J. Vanderkaay, G.W. Mayr, and P.J.M. Van Haastert. 1994. Role of phospholipase C in Dictyostelium: Formation of inositol 1,4,5-trisphosphate and normal devel- 
opment in cells lacking phospholipase $\mathrm{C}$ activity. EMBO /. 13: $1601-1609$.

Dynes, J., A. Clark, G. Shaulsky, A. Kuspa, W. Loomis, and R. Firtel. 1994. LagC is required for cell-cell interactions that are essential for cell-type differentiation in Dictyostelium. Genes \& Dev. 8: 948-958.

Early, A.E. and J.G. Williams. 1988. A Dictyostelium presporespecific gene is transcriptionally repressed by DIF in vitro. Development 103: 519-524.

Early, A.E., M.J. Gaskell, D. Traynor, and J.G. Williams. 1993. Two distinct populations of prestalk cells within the tip of the migratory Dictyostelium slug with differing fates at culmination. Development 118: 353-362.

Errede, B. and D. Levin. 1993. A conserved kinase cascade for MAP kinase activation in yeast. Curr. Opin. Cell Biol. 5: 254-260.

Esch, R.K. 1991. "Expression of the developmentally-regulated, prestalk-specific ras gene of Dictyostelium discoideum." Ph.D. thesis, University of California, San Diego, CA.

Esch, R.K. and R.A. Firtel. 1991. cAMP and cell sorting control the spatial expression of a developmentally essential celltype-specific ras gene in Dictyostelium. Genes \& Dev. 5; $9-21$.

Esch, R.K., P.K. Howard, and R.A. Firtel. 1992. Regulation of the Dictyostelium cAMP-induced, prestalk- specific DdrasD gene: Identification of cis-acting elements. Nucleic Acids Res. 20: 1325-1332.

Fosnaugh, K.L. and W.F. Loomis. 1993. Enhancer regions responsible for temporal and cell-type-specific expression of a spore coat gene in Dictyostelium. Dev. Biol. 157: 38-48.

Franke, J. and R.H. Kessin. 1992. The cyclic nucleotide phosphodiesterases of Dictyostelium discoideum: Molecular genetics and biochemistry. Cell. Signal. 4: 471-478.

Gaskins, C., M. Maeda, and R. Firtel. 1994. Identification and functional analysis of a developmentally regulated extracellular signal-regulated kinase gene in Dictyostelium discoideum. Mol. Cell. Biol. 14: 6996-7012.

Gee, K., F. Russell, and J.D. Gross. 1994. Ammonia hypersensitivity of slugger mutants of Dictyostelium discoideum. I. Cell Sci. 107: 701-708.

Gomer, R.H. and R.A. Firtel. 1987. Cell-autonomous determination of cell-type choice in Dictyostelium development by cell-cycle phase. Science 237: 758-762.

Gomer, R.H., D. Armstrong, B.H. Leichtling, and R.A. Firtel. 1986a. cAMP induction of prespore and prestalk gene expression in Dictyostelium is mediated by the cell-surface cAMP receptor. Proc. Natl. Acad. Sci. 83: 8624-8628.

Gomer, R.H., S. Datta, and R.A. Firtel. 1986b. Cellular and subcellular distribution of a cAMP-regulated prestalk protein and prespore protein in Dictyostelium discoideum: A study on the ontogeny of prestalk and prespore cells. J. Cell Biol. 103: 1999-2015.

Gomer, R.H., I.S. Yuen, and R.A. Firtel. 1991. A secreted $80 \times 10^{3} \mathrm{Mr}$ protein mediates sensing of cell density and the onset of development in Dictyostelium. Development 112: $269-278$

Gross, J.D., J. Bradbury, R.R. Kay, and M.J. Peacey. 1983. Intracellular $\mathrm{pH}$ and the control of cell differentiation in Dictyostelium discoideum. Nature 303: 244-245.

Gross, J.D., M.J. Peacey, and R. Pogge Von Strandmann. 1988. Plasma membrane proton pump inhibition and stalk cell differentiation in Dictyostelium discoideum. Differentiation 38: 91-98.

Haberstroh, L. and R.A. Firtel. 1990. A spatial gradient of expression of a CAMP-regulated prespore cell type specific gene in Dictyostelium. Genes \& Dev. 4: 596-612.
Haberstroh, L., J. Galindo, and R.A. Firtel. 1991. Developmental and spatial regulation of a Dictyostelium prespore gene: cisacting elements and a cAMP-induced, developmentally regulated DNA binding activity. Development 113: 947-958.

Hadwiger, J.A. and R.A. Firtel. 1992. Analysis of G $\alpha 4$, a G-protein subunit required for multicellular development in Dictyostelium. Genes \& Dev. 6: 38-49.

Hadwiger, J., S. Lee, and R. Firtel. 1994. The Ga subunit G $\alpha 4$ couples to pterin receptors and identifies a signaling pathway that is essential for multicellular development in Dictyostelium. Proc. Nat1. Acad. Sci. 91: 10566-10570.

Hall, A.L., J. Franke, M. Faure, and R.H. Kessin. 1993. The role of the cyclic nucleotide phosphodiesterase of Dictyostelium discoideum during growth, aggregation, and morphogenesis: Overexpression and localization studies with the separate promoters of the PDE. Dev. Biol. 157: 73-84.

Haribabu, B. and R.P. Dottin. 1986. Pharmacological characterization of cyclic AMP receptors mediating gene regulation in Dictyostelium discoideum. Mol. Cell. Biol. 6: 2402-2408.

Harwood, A.J., N.A. Hopper, M.N. Simon, D.M. Driscoll, M. Veron, and J.G. Williams. 1992. Culmination in Dictyostelium is regulated by the cAMP-dependent protein kinase. Cell 69: 615-624.

Harwood, A.J., A. Early, and J.G. Williams. 1993. A repressor controls the timing and spatial localisation of stalk cell-specific gene expression in Dictyostelium. Development 118: 1041-1048.

Harwood, A., S. Plyte, J. Woodgett, H. Strutt, and R. Kay. 1995. Glycogen synthetase kinase 3 (GSK-3) regulates cell fate in Dictyostelium. Cell 80: 139-148.

Hjorth, A.L., N.C. Khanna, and R.A. Firtel. 1989. A trans-acting factor required for cAMP-induced gene expression in Dictyostelium is regulated developmentally and induced by cAMP. Genes \& Dev. 3: 747-759.

Hjorth, A.L., C. Pears, J.G. Williams, and R.A. Firtel. 1990. A developmentally regulated trans-acting factor recognizes dissimilar $\mathrm{G} / \mathrm{C}$-rich elements controlling a class of cAMPinducible Dictyostelium genes. Genes \& Dev. 4: 419-432.

Hopper, N.A., C. Anjard, C.D. Reymond, and J.G. Williams. 1993a. Induction of terminal differentiation of Dictyostelium by cAMP-dependent protein kinase and opposing effects of intracellular and extracellular cAMP on stalk cell differentiation. Development 119: 147-154.

Hopper, N.A., A.J. Harwood, S. Bouzid, M. Veron, and J.G. Williams. 1993b. Activation of the prespore and spore cell pathway of Dictyostelium differentiation by cAMP-dependent protein kinase and evidence for its upstream regulation by ammonia. EMBO I. 12: 2459-2466.

Howard, P.K., B.M. Sefton, and R.A. Firtel. 1992. Analysis of a spatially regulated phosphotyrosine phosphatase identifies tyrosine phosphorylation as a key regulatory pathway in Dictyostelium. Cell 71: 637-647.

_ 1993. Tyrosine phosphorylation of actin in Dictyostelium associated with cell-shape changes. Science 259: $241-$ 244.

Howard, P., M. Gamper, T. Hunter, and R. Firtel. 1994. Regulation by protein-tyrosine phosphatase PTP2 is distinct from that by PTP1 during Dictyostelium growth and development. Mol. Cell. Biol. 14: 5154-5164.

Insall, R. and R.R. Kay. 1990. A specific DIF binding protein in Dictyostelium. EMBO f. 9: 3323-3328.

Insall, R., O. Nayler, and R.R. Kay. 1992. DIF-1 induces its own breakdown in Dictyostelium. EMBO /. 11: 2849-2854.

Insall, R., A. Kuspa, P. Lilly, G. Shaulsky, L. Levin, W. Loomis, and P. Devreotes. 1994a. CRAC, a cytosolic protein containing a pleckstrin homology domain, is required for receptor 
and $G$ protein-mediated activation of adenylyl cyclase in Dictyostelium. I. Cell Biol. 126: 1537-1545.

Insall, R.H., R.D.M. Soede, P. Schaap, and P.N. Devreotes. 1994b. Two cAMP receptors activate common signaling pathways in Dictyostelium. Mol. Biol. Cell 5: 703-711.

Jackson, C., J. Konopka, and L. Hartwell. 1991. S. cerevisiae alpha pheromone receptors activate a novel signal transduction pathway for mating partner discrimination. Cell 67: $389-402$.

Jermyn, K.A. and J.G. Williams. 1991. An analysis of culmination in Dictyostelium using prestalk and stalk-specific cell autonomous markers. Development 111: 779-787.

Jermyn, K.A., M. Berks, R.R. Kay, and J.G. Williams. 1987. Two distinct classes of prestalk-enriched mRNA sequences in Dictyostelium discoideum. Development 100: 745-755.

Jessell, T. and D. Melton. 1992. Diffusible factors in vertebrate embryonic induction. Cell 68: 257-270.

Johnson, R.L., P.J.M. Van Haastert, A.R. Kimmel, C.L. Saxe, B. Jastorff, and P.N. Devreotes. 1992. The cyclic nucleotide specificity of three cAMP receptors in Dictyostelium. I. Biol. Chem. 267: 4600-4607.

Kambayashi, Y., S. Bardhan, K. Takahashi, S. Tsuzuki, H. Inui, T. Hamakubo, and T. Inagam. 1993. Molecular cloning of a novel angiotensin II receptor isoform involved in phosphotyrosine phosphatase inhibition. I. Biol. Chem. 268: 2454324546.

Kay, R.R. 1989. Evidence that elevated intracellular cyclic AMP triggers spore maturation in Dictyostelium. Development 105: 753-759.

Kay, R.R., S. Large, D. Traynor, and O. Nayler. 1993. A localized differentiation-inducing-factor sink in the front of the Dictyostelium slug. Proc. Natl. Acad. Sci. 90: 487-491.

Kesbeke, F., P.J.M. Van Haastert, and P. Schaap. 1986. Cyclic AMP relay and cyclic AMP-induced cyclic GMP accumulation during development of Dictyostelium discoideum. FEMS Microbiol. Lett. 34: 85-89.

Kesbeke, F., B.E. Snaar-Jagalska, and P.J.M. Van Haastert. 1988. Signal transduction in Dictyostelium fgd A mutants with a defective interaction between surface cAMP receptors and a GTP-binding regulatory protein. I. Cell Biol. 107: 521-528.

Kesbeke, F., P.J.M. Van Haastert, R.J.W. De Wit, and B.E. SnaarJagalska. 1990. Chemotaxis to cyclic AMP and folic acid is mediated by different G-proteins in Dictyostelium-discoideum. J. Cell Sci. 96: 669-673.

Kimmel, A.R. and R.A. Firtel. 1991. cAMP signal transduction pathways regulating development of Dictyostelium discoideum. Curr. Opin. Genet. Dev. 1: 383-390.

Klein, R., R. Thiery, and I. Tatischeff. 1990. Dictyopterin, 6-(Dthreo-1,2-dihydroxypropyl)-pterin, a new natural isomer of L-biopterin-Isolation from vegetative cells of Dictyostelium discoideum and identification. Eur. I. Biochem. 187: 665-669.

Kubohara, Y. and K. Okamoto. 1994. Cytoplasmic $\mathrm{Ca}^{2+}$ and $\mathrm{H}^{+}$ concentrations determine cell fate in Dictyostelium discoideum. FASEB I. 8: 869-874.

Kumagai, A., M. Pupillo, R. Gundersen, R. Miake-Lye, P.N. Devreotes, and R.A. Firtel. 1989. Regulation and function of $\mathrm{G} \alpha$ protein subunits in Dictyostelium. Cell 57: 265-275.

Kumagai, A., J.A. Hadwiger, M. Pupillo, and R.A. Firtel. 1991. Molecular genetic analysis of two $\mathrm{G} \alpha$ protein subunits in Dictyostelium. J. Biol. Chem. 266: 1220-1228.

Kuwayama, H., S. Ishida, and P. Van Haastert. 1993. Non-chemotactic Dictyostelium discoideum mutants with altered cGMP signal transduction. J. Cell Biol. 123: 1453-1462.

Kwong, L., Y.J. Xie, J. Daniel, S.M. Robbins, and G. Weeks. 1990. A Dictyostelium morphogen that is essential for stalk cell formation is generated by a subpopulation of prestalk cells. Development 110: 303-310.

Lilly, P.J. and P.N. Devreotes. 1994. Identification of CRAC, a cytosolic regulator required for guanine nucleotide stimulation of adenylyl cyclase in Dictyostelium. I. Biol. Chem. 269: 14123-14129.

Liu, G., H. Kuwayama, S. Ishida, and P.C. Newell. 1993. The role of cyclic GMP in regulating myosin during chemotaxis of Dictyostelium-Evidence from a mutant lacking the normal cyclic GMP response to cyclic AMP. I. Cell Sci. 106: 591-596.

Loomis, W.F. 1975. Dictyostelium discoideum: A developmental system. Academic Press, New York.

Loomis, W.F., ed. 1982. The Development of Dictyostelium discoideum. Academic Press, New York.

Louis, J., G. Ginsburg, and A. Kimmel. 1994. A cAMP receptor regulates axial patterning and cellular differentiation during late development of Dictyostelium. Genes \& Dev. 8: 20522061

Maeda, Y. 1993. Pattern formation in a cell-cycle dependent manner during the development of Dictyostelium discoideum. Dev. Growth Differ. 35: 609-616.

Maeda, Y. and M. Maeda. 1973. The calcium content of the cellular slime mold, Dictyostelium discoideum, during development and differentiation. Exp. Cell Res. 82: 125-130.

Mann, S.K. and R.A. Firtel. 1989. Two-phase regulatory pathway controls cAMP receptor-mediated expression of early genes in Dictyostelium. Proc. Natl. Acad. Sci. 86: 1924 1928.

- 1991. A developmentally regulated, putative serine/ threonine protein kinase is essential for development in Dictyostelium. Mech. Dev. 35: 89-102.

- 1993. cAMP-dependent protein kinase differentially regulates prestalk and prespore differentiation during Dictyos telium development. Development 119: 135-146.

Mann, S., D. Richardson, S. Lee, A. Kimmel, and R. Firtel. 1994. Expression of cAMP-dependent protein kinase in prespore cells is sufficient to induce spore cell differentiation in Dictyostelium. Proc. Natl. Acad. Sci. 91: 10561-10565.

McDonald, S.A. 1986. Cell-cycle regulation of center initiation in Dictyostelium discoideum. Dev. Biol. 117: 546-549.

McRobbie and P.C. Newell. 1984. Chemoattractant-mediated changes in cytoskeletal actin of cellular slime moulds. I. Cell Sci. 68: 139-151.

Mee, J.D., D.M. Tortolo, and M.B. Coukell. 1986. Chemotaxisassociated properties of separated prestalk and prespore cells of Dictyostelium discoideum. Biochem. Cell. Biol. 64: 722732.

Mehdy, M.C. and R.A. Firtel. 1985. A secreted factor and cyclic AMP jointly regulate cell-type-specific gene expression in Dictyostelium discoideum. Mol. Cell. Biol. 5: 705-713.

Mehdy, M.C., D. Ratner, and R.A. Firtel. 1983. Induction and modulation of cell-type specific gene expression in Dictyos telium. Cell 32: 763-771.

Meyer, T., L. Stryer, and H. Schulman. 1994. Dual role of calmodulin in autophosphorylation of multifunctional CaM kinase may underlie decoding of calcium signals. Neuron 12: 943-956.

Milne, J.L.S., L. Wu, M.J. Caterina, and P.N. Devreotes. 1995. Seven helix cAMP receptors stimulate $\mathrm{Ca}^{2+}$ entry in the absence of functional G proteins in Dictyostelium. I. Biol. Chem. (in press).

Mukoyama, M., M. Nakajima, M. Horiuchi, H. Sasamura, R. Pratt, and V. Dzau. 1993. Expression cloning of type 2 angiotensin II receptor reveals a unique class of seven-transmembrane receptors. J. Biol. Chem. 268: 24539-24542. 
Newell, P.C. and G. Liu. 1992. Streamer-F mutants and chemotaxis of Dictyostelium. BioEssays 14: 473-479.

Okaichi, K., A.B. Cubitt, G.S. Pitt, and R.A. Firtel. 1992. Amino acid substitutions in the Dictyostelium $\mathrm{G} \alpha$ subunit G $\alpha 2$ produce dominant negative phenotypes and inhibit the activation of adenylyl cyclase, guanylyl cyclase, and phospholipase-C. Mol. Biol. Cell 3: 735-747.

Oyama, M. and D.D. Blumberg. 1986. Interaction of CAMP with the cell-surface receptor induces cell-type specific mRNA accumulation in Dictyostelium discoideum. Proc. Natl. Acad. Sci. 83: 4819-4823.

Palczewski, K., J. Buczylko, M.W. Kaplan, A.S. Polans, and J.W. Crabb. 1991. Mechanism of rhodopsin kinase activation. $/$. Biol. Chem. 266: 12949-12955.

Pavlovic, J., B. Haribabu, and R.P. Dottin. 1989. Identification of a signal transduction response sequence element necessary for induction of a Dictyostelium discoideum gene by extracellular cyclic AMP. Mol. Cell. Biol. 9: 4660-4669.

Pears, C.J. and J.G. Williams. 1988. Multiple copies of a G-rich element upstream of a cAMP-inducible Dictyostelium gene are necessary but not sufficient for efficient gene expression. Nucleic Acids Res. 16: 8467-8486.

Pears, C.J., H.M. Mahbubani, and J.G. Williams. 1985. Characterization of two highly diverged but developmentally coregulated cysteine proteinases in Dictyostelium discoideum. Nucleic Acids Res. 13: 8853-8866.

Perrimon, N. 1995. Hedgehog and beyond. Cell 80: 517-520.

Pitt, G.S., N. Milona, J. Borleis, K.C. Lin, R.R. Reed, and P.N. Devreotes. 1992. Structurally distinct and stage-specific adenylyl cyclase genes play different roles in Dictyostelium development. Cell 69: 305-315.

Pitt, G.S., R. Brandt, K.C. Lin, P.N. Devreotes, and P. Schaap. 1993. Extracellular cAMP is sufficient to restore developmental gene expression and morphogenesis in Dictyostelium cells lacking the aggregation adenylyl cyclase (ACA). Genes \& Dev. 7: 2172-2180.

Powell-Coffman, J.A. 1994. "Regulation of prespore-specific transcription in Dictyostelium discoideum." Ph.D. thesis, University of California, San Diego, CA.

Powell-Coffman, J. and R. Firtel. 1994. Characterization of a novel Dictyostelium discoideum prespore-specific gene, PspB, reveals conserved regulatory sequences. Development 120: 1601-1611.

Powell-Coffman, J., G. Schnitzler, and R. Firtel. 1994. A GBFbinding site and a novel AT element define the minimal sequences sufficient to direct prespore-specific expression in Dictyostelium. Mol. Cell. Biol. 14: 5840-5849.

Raper, K.B. 1940. Pseudoplasmodium formation and organization in Dictyostelium discoideum. I. Elisha Mitchell Sci. Soc. 56: 241-282.

Reymond, C.D., R.H. Gomer, M.C. Mehdy, and R.A. Firtel. 1984. Developmental regulation of a Dictyostelium gene encoding a protein homologous to mammalian ras protein. Cell 39: 141-148.

Reymond, C.D., R.H. Gomer, W. Nellen, A. Theibert, P. Devreotes, and R. Firtel. 1986. Phenotypic changes induced by a mutated ras gene during the development of Dictyos. telium transformants. Nature 323: 340-343.

Richardson, D.L., C.B. Hong, and W.F. Loomis. 1991. A prespore gene, Dd31, expressed during culmination of Dictyostelium discoideum. Dev. Biol. 144: 269-280.

Richardson, D., W. Loomis, and A. Kimmel. 1994. Progression of an inductive signal activates sporulation in Dictyostelium discoideum. Development 120: 2891-2899.

Riley, B.B., B.R. Jensen, and S.L. Barclay. 1989. Conditions that elevate intracellular cAMP levels promote spore formation in Dictyostelium. Differentiation 41: 5-13.

Saxe, C.L., G.T. Ginsburg, J.M. Louis, R. Johnson, P.N. Devreotes, and A.R. Kimmel. 1993. CAR2, a prestalk cAMP receptor required for normal tip formation and late development of Dictyostelium discoideum. Genes \& Dev. 7: 262272.

Schaap, P. and R. Van Driel. 1985. Induction of post-aggregative differentiation in Dictyostelium discoideum by cAMP. Evidence for the involvement of the cell surface cAMP receptor. Exp. Cell Res. 159: 388-398.

Schaap, P., M.M. Van Lookeren Campagne, R. Van Driel, W. Spek, P.J.M. Van Haastert, and J. Pinas. 1986. Postaggregative differentiation induction by cyclic AMP in Dictyostelium: Intracellular transduction pathway and requirement for additional stimuli. Dev. Biol. 118: 52-63.

Schlatterer, C., G. Knoll, and D. Malchow. 1992. Intracellular calcium during chemotaxis of Dictyostelium discoideum: A new Fura-2 derivative avoids sequestration of the indicator and allows long-term calcium measurements. Eur. I. Cell Biol. 58: 172-181.

Schnitzler, G., W. Fischer, and R. Firtel. 1994. Cloning and characterization of the G-box binding factor, an essential component of the developmental switch between early and late development in Dictyostelium. Genes \& Dev. 8: 502-514.

Schnitzler, G.R., C. Briscoe, J.M. Brown, and R.A. Firtel. 1995. Serpentine cAMP receptors may act through a G-proteinindependent pathway to induce post-aggregative development in Dictyostelium. Cell 81: 737-745.

Segall, J., A. Kuspa, G. Shaulsky, M. Ecke, M. Maeda, C. Gaskins, R. Firtel, and W. Loomis. 1995. A MAP kinase necessary for receptor-mediated activation of adenylyl cyclase in Dictyostelium. I. Cell Biol. 128: 405-413.

Siegert, F. and C.J. Weijer. 1991. Analysis of optical density wave propagation and cell movement in the cellular slime mold Dictyostelium discoideum. Physica D 49: 224-232.

- 1992 . Three-dimensional scroll waves organize Dictyostelium slugs. Proc. Natl. Acad. Sci. 89: 6433-6437.

Siegfried, E., L. Perkins, T. Capaci, and N. Perrimon. 1990. Putative protein kinase product of the Drosophila segment polarity gene, zeste-white 3. Nature 345: 825-829.

Siegfried, E., T.-B. Chou, and N. Perrimon. 1992. wingless signalling acts through zeste-white 3 the Drosophila homolog of glycogen synthase kinase-3 to regulate engrailed and establish cell fate. Cell 71: 1167-1179.

Simon, M.N., O. Pelegrini, M. Veron, and R.R. Kay. 1992. Mutation of protein kinase A causes heterochronic development of Dictyostelium. Nature 356: 171-172.

Simpson, P., L. Ruel, P. Heitzler, and M. Bourouis. 1993. A dual role for the protein kinase shaggy in repression of achaetescute. Development (Suppl.): 29-39.

Soede, R.D.M., R.H. Insall, P.N. Devreotes, and P. Schaap. 1994. Extracellular cAMP can restore development in Dictyostelium cells lacking one, but not two subtypes of early cAMP receptors (cARs). Evidence for involvement of cAR1 in aggregative gene expression. Development 120: 1997-2002.

Stephens, L., A. Smrcka, F.T. Cooke, T.R. Jackson, P.C. Sternweis, and P.T. Hawkins. 1994. A novel phosphoinositide 3 kinase activity in myeloid-derived cells is activated by $G$ protein beta gamma subunits. Cell 77: 83-93.

Sternfeld, J. and C.N. David. 1982. Fate and regulation of anterior-like cells in Dictyostelium slugs. Dev. Biol. 93:111118.

Sun, T.J. and P.N. Devreotes. 1991. Gene targeting of the aggregation stage cAMP receptor cARl in Dictyostelium. Genes \& Dev. 5: 572-582.

Tan, J.L. and J.A. Spudich. 1990. Developmentally regulated 
protein-tyrosine kinase genes in Dictyostelium-discoideum. Mol. Cell. Biol. 10: 3578-3583.

Tang, W. and A. Gilman. 1992. Adenylyl cyclases. Cell 70: 869872.

Tirlapur, U., J. Gross, and V. Nanjundiah. 1991. Spatial variation of sequestered calcium in the multicellular stage of Dictyostelium discoideum as assayed by chlortetracycline fluorescence. Differentiation 48: 137-146.

Tomchik, K.J. and P.N. Devreotes. 1981. Adenosine 3', 5' -monophosphate waves in Dictyostelium discoideum: A demonstration by isotope dilution-fluorography technique. Science 212: 443-446.

Touhara, K., J. Inglese, J. Pitcher, G. Shaw, and R. Lefkowitz. 1994. Binding of $\mathrm{G}$ protein beta gamma-subunits to pleckstrin homology domains. J. Biol. Chem. 269: 10217-10220.

Town, C. and J. Gross. 1978. The role of cyclic nucleotides and cell agglomeration in postaggregative enzyme synthesis in Dictyostelium discoideum. Dev. Biol. 63: 412-420.

Town, C.D., J.D. Gross, and R.R. Kay. 1976. Cell differentiation without morphogenesis in Dictyostelium discoideum. $\mathrm{Na}$ ture 262: 717-7194.

Traynor, D., R.H. Kessin, and J.G. Williams. 1992. Chemotactic sorting to cAMP in the multicellular stages of Dictyostelium development. Proc. Natl. Acad. Sci. 89: 8303-8307.

Van der Geer, P., T. Hunter, and R.A. Lindberg. 1994. Receptor protein-tyrosine kinases and their signal transduction pathways. Annu. Rev. Cell Biol. 10: 251-337.

Van Haastert, P.J.M., R.J.W. De Wit, P.M.W. Janssens, F. Kesbeke, B.E. Snaar-Jagalska, M.M. Van Lookeren Campagne, and T.M. Konijn. 1987. Adaptation of Dictyostelium discoideum cells to chemotactic signals. Molecular mechanisms of desensitization to signal molecules. Springer-Verlag, Heidelberg, Germany.

Wang, M. and P. Schaap. 1985. Correlations between tip dominance, prestalk/prespore pattern, and cAMP-relay efficiency in slugs of Dictyostelium discoideum. Differentiation 30: 7-14.

1989. Ammonia depletion and DIF trigger stalk cell differentiation in intact Dictyostelium discoideum slugs. Development 105: 569-574.

Wang, M., R.J. Aerts, W. Spek, and P. Schaap. 1988. Cell cycle phase in Dictyostelium discoideum is correlated with the expression of cyclic AMP production, detection, and degradation. Dev. Biol. 125: 410-416.

Weijer, C.J., G. Duschl, and C.N. David. 1984a. A revision of the Dictyostelium discoideum cell cycle. /. Cell Sci. 70: 111131.

- 1984b. Dependence of cell-type proportioning and sorting on cell cycle phase in Dictyostelium discoideum. I. Cell Sci. 70: 133-145.

Williams, J.G. 1991. Regulation of cellular differentiation during Dictyostelium morphogenesis. Curr. Opin. Genet. Dev. 1: 358-362.

Williams, J.G. and K.A. Jermyn. 1991. Cell sorting and positional differentiation during Dictyostelium morphogenesis. Cell-cell interactions in early development, pp. 261-272. Wiley-Liss, New York.

Williams, J.G., K.T. Duffy, D.P. Lane, S.J. McRobbie, A.J. Harwood, D. Traynor, R.R. Kay, and K.A. Jermyn. 1989. Origins of the prestalk-prespore pattern in Dictyostelium development. Cell 59: 1157-1163.

Williams, J.G., A.J. Harwood, N.A. Hopper, M.N. Simon, S. Bouzid, and M. Veron. 1993a. Regulation of Dictyostelium morphogenesis by cAMP-dependent protein kinase. Phil. Trans. R. Soc. Lond. (B) Biol. Sci. 340: 305-313.

Williams, J., N. Hopper, A. Early, D. Traynor, A. Harwood, T.
Abe, M. Simon, and M. Veron. 1993b. Interacting signalling pathways regulating prestalk cell differentiation and movement during the morphogenesis of Dictyostelium. Development (Suppl): 1-7.

Wu, L., C. Gaskins, R. Gundersen, J. Hadwiger, R. Johnson, G. Pitt, R. Firtel, and P. Devreotes. 1994a. Signal transduction by G-proteins in Dictyostelium discoideum. Handbook of experimental pharmacology, vol. 108/II GTPases in biology II (ed. B. Dickey and L. Birnbaumer), pp. 335-349. SpringerVerlag Publications, Berlin, Germany.

Wu, L., C. Gaskins, K. Zhou, R. Firtel, and P. Devreotes. 1994b. Cloning and targeted mutations of $\mathrm{G} \alpha 7$ and $\mathrm{G} \alpha 8$, two devel opmentally regulated G protein $\alpha$-subunit genes in Dictyostelium. Mol. Cell. Biol. 5: 691-702.

Wu, L.-I., H. Kuwayama, P.J.M. Van Haastert, and P.N. Devreotes. 1995. The G protein beta-subunit is essential for multiple responses to chemoattractants in Dictyostelium. I. Cell Biol. (in press).

Yuen, I.S., C. Taphouse, K.A. Halfant, and R.H. Gomer. 1991. Regulation and processing of a secreted protein that mediates sensing of cell density in Dictyostelium. Development 113: $1375-1385$. 


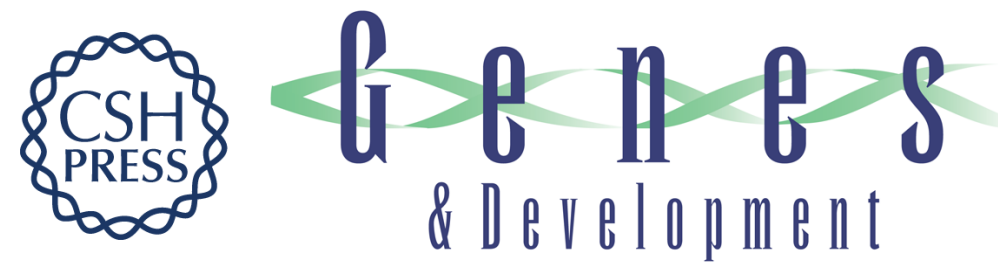

\section{Integration of signaling information in controlling cell-fate decisions in Dictyostelium.}

R A Firtel

Genes Dev. 1995, 9:

Access the most recent version at doi:10.1101/gad.9.12.1427

References This article cites 144 articles, 70 of which can be accessed free at:

http://genesdev.cshlp.org/content/9/12/1427.full.html\#ref-list-1

License

Email Alerting

Service

Receive free email alerts when new articles cite this article - sign up in the box at the top right corner of the article or click here.

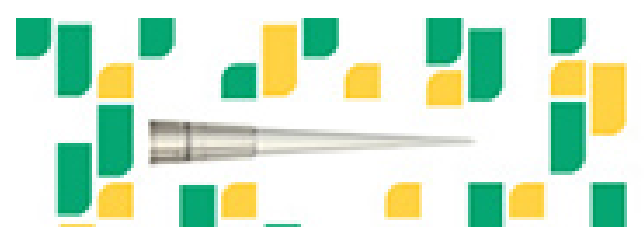

Focused on your science.

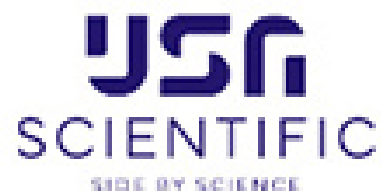

Copyright (c) Cold Spring Harbor Laboratory Press 